\title{
The Role of Realised Volatility in the Athens Stock Exchange
}

\author{
Dimitrios D. Thomakos* \\ University of Peloponnese, Greece \\ Rimini Centre for Economic Analysis, Italy \\ Michail S. Koubouros \\ City College and University of Liverpool, United Kingdom
}

\begin{abstract}
Using a newly developed dataset of daily, value-weighted market returns we construct and analyze the monthly realized volatility of the Athens Stock Exchange (A.S.E.) from 1985 to 2003. Our analysis focuses on the distributional and time series properties of the realized volatility series and on assessing the connection between realized volatility and returns through a multi-factor asset pricing model. In particular, we find strong evidence on the existence of a volatility feedback effect and a leverage effect, and on the existence of asymmetries between lagged returns and volatility. Furthermore, we examine the cross-sectional distribution of unconditional loadings on the realized risk factor(s) for different sets of characteristics-sorted common stock portfolios. We find that realized risk is a significantly priced factor in A.S.E. and its high explanatory power for the cross-section of portfolio average returns is independent of any return variation related to the market (CAPM) or size and book-to-market (Fama-French) factors. We discuss our findings in the context of the recent literature on realized volatility and feedback effects, as well as the literature on the pricing power of realized risk (JEL: G12)
\end{abstract}

Keywords: realized volatility, leverage effect, volatility feedback effect, asset pricing, A.S.E.

\section{Introduction}

There is an exploding literature that studies the relationship between

* We would like to thank, without implicating, an anonymous referee, Gikas Hardouvelis, Dimitrios Malliaropoulos, an anonymous referee and the seminar participants at the University of Peloponnese and the University of Piraeus, for their comments and criticisms. An earlier version of this paper was presented at the 4th Conference on Research on Economic Theory and Econometrics. Any remaining errors are ours.

(Multinational Finance Journal, 2011, vol. 15, no. 1/2, pp. 87-124)

(C) Multinational Finance Society, a nonprofit corporation. All rights reserved.

DOI: $10.17578 / 15-1 / 2-3$ 
volatility and returns with a large number of, frequently conflicting, sets of results. Most of the related empirical work is done in the context of (and with data from) highly efficient markets. However, it is of theoretical and practical interest to examine whether any of the empirical regularities that characterize the linkages between volatility and asset returns are present in the context of smaller, less efficient markets. There is always a possibility that the sign and magnitude of any such relationships may be different in a smaller market and, in addition, there may be different implications for asset pricing, portfolio choice and risk management.

In this paper we use a new dataset of daily, value-weighted market returns for Greece to construct and analyze the monthly realized volatility of the Athens Stock Exchange (A.S.E.). We examine whether the realized volatility series exhibits any of the, temporal and distributional, regularities found in the related literature and then explore the relationship between volatility and the cross-section of average returns. The A.S.E. market formally exists since 1876 as an independent financial entity and started its operations in 1880, dealing with bonds issued for national loans and on stocks of the National Bank of Greece. ${ }^{1}$ In 1909 the A.S.E. was allowed to deal with state-issued bonds and treasury bills as well as with stocks of incorporated firms.

The first part of our work is related to two lines of the volatility literature: the first is the line that deals with the construction and properties of model-free measures of volatility (including realized and implied volatility), and second is the line that examines the, so-called, leverage effect; this is the presence of an asymmetric response of volatility to past returns - past returns being negatively correlated to current volatility. There is a high degree of overlap between these two lines of research, since the construction of volatility and its analysis usually appear together. The concept of realized volatility has been around for a number of years, see for example Merton (1980), Poterba and Summers (1986), French et al. (1987), Schwert (1990) and Campbell et al. (2001) who used daily returns in constructing monthly stock return volatilities. However, little was known about the properties of the realized volatility estimates until recently, with the advent of higher frequency data sets and the ease of computation of daily realized volatility. Andersen and Bollerslev (1998) and Barndorff-Nielsen and Shephard (2001a and b) have shown, using the theory of quadratic variation, that the realized volatility estimator is a consistent estimator

1. The National Bank of Greece, one of the largest commercial banks in modern Greek history, does not coincide with the Central Bank of Greece 
of the actual volatility. This is an interesting and very practical result for it is model-free and does not depend upon any particular parametric form for either the returns or the volatility. Recent important papers, focusing however in daily realized volatility, include the work by Andersen et al. (2001a, b and c). Finally, for a concentrated exposition on volatility measurement see the article of Andersen, Bollerslev and Diebold in the Handbook of Financial Econometrics. From previous work on the asymmetric response of volatility to past returns we mention, among others, Pindyck (1984), French et al. (1987), Campbell and Hentschel (1992), and Nelson (1991), Engle and $\mathrm{Ng}$ (1993), Duffee (1995), Bekaert and Wu (2000) and Andersen et al. (2001c), Bollerslev and Zhou (2006). To preview our results from the analysis of realized volatility, there appear strong indications that the A.S.E. market behaves like a textbook case: not only there is strong evidence of financial leverage, but there appears that the A.S.E. market has a time-varying risk premium that is an increasing function of volatility; that premium increases with an anticipated increase in volatility thus raising the anticipated return on equity, which in turn implies an immediate decline on equity price. ${ }^{2}$

In the second part of our work we examine whether contemporaneous and long-term measured market realized risk could be a priced factor in A.S.E. common stock returns. To the best of our knowledge this is the first study that examines the usefulness of realized risk as a priced factor in the Greek stock market. There is now an extensive literature that provides both theoretical and empirical support to the relationship between exposures to aggregate market volatility and average excess returns (see, for example, Chen (2003), Ang, Hodrick, Xing and Zhang (2006) and Guo and Whitelaw (2006)). Following these findings we consider our empirical asset pricing tests to be an obvious and practical extension of the first part of the paper, as they point toward both the usefulness of our realized volatility analysis and the implications of realized risk in the A.S.E. market. Our pricing results are basically suggestive of a rather clear linear relationship between factor loadings on realized aggregate volatility (either realized volatility or logarithmic standard deviation) and this relationship is independent of

2. There are a number of past papers that deal with the volatility of the ASE but in a parametric, model-based context, and addressing different issues than the ones we are attempting to deal with here. A representative sample includes, in chronological order: Phylakits, Kavussanos and Manalis (1999), Chortareas, McDermont and Ritsatos (2000), Apergis and Eleftheriadou (2001), Kavussanos and Dockery (2001), Siourounis (2002), Maris et al. (2004), Vougas (2004), Athanassiou, Kollias and Syriopoulos (2006), Floros and Vougas (2006), and Drimbetas, Sariannidis and Porfiris (2007). Note that we have not included previous works that deal with futures or derivatives of the ASE. 
any aggregate market, size or book-to-market effects, as these are captured by the popular three-factor Fama-French (1993) model.

The rest of the paper is organized as follows. In section II we discuss the construction of our data set; in section III we discuss the statistics used in assessing the temporal and distributional properties of the constructed realized volatility and associated returns, and then present the asymmetry regressions and associated results about the presence and magnitude of the leverage effect for the Greek market; in section IV we present the results of our asset pricing exercise using the realized volatility measurements of the previous sections. Finally, in section V we offer some concluding remarks. Tables and figures are aggregated in the appendix.

\section{Construction of Data}

The basis of our data set is a new, daily, value-weighted market index for A.S.E. that starts in January of 1985 and runs until the end of June of 2003. The index was constructed using individual stock data from the Finance Statistics \& Fundamental Analysis Data Base in Athens (EFFECT). The most important novelty, of practical significance, about this index is that in its construction we use - in a consistent manner - all available traded common stocks for the whole sample period. We sort all currently traded common stocks according to their previous daily market capitalization and we define the total A.S.E. daily return index as the value-weighted average of all listed individual stock returns in each day. Thus our aggregate market series can be viewed as a dynamic daily portfolio strategy based on relative size, in the sense that the investor dynamically rebalances her portfolio at the beginning of each day using last day's firm-specific market value information. Therefore, the index should be more representative of the whole market from what is currently available. ${ }^{3}$ We anticipate that the volatility measure we derive from this index will also be representative of the underlying market volatility. We finally note that this index has not been used before in any analyses of the Greek stock market.

The methodology used in constructing the index is the following. Let $P_{k(t)}^{i}$ denote the closing price of stock $i$ at trading day $k$ of month $t$ and $D^{i, \text { year }}$ denote the corresponding annual dividend paid. Assuming an average of 20 trading days per month, the net return on stock $i, R_{k(t)}^{i}$, is

3. See our discussion below for how our index differs from what is publicly available for the ASE. 
calculated as:

$$
R_{k(t)}^{i}=\frac{P_{k(t)}^{i}+\left(\frac{D^{i, y e a r}}{240}\right)}{P_{k-1(t)}}-1,
$$

Consider next the relative market share of each stock $i$ but at period $k-1(t)$, say $0 \leq W_{k-1(t)}^{i}<1$. If $I_{k-1(t)}$ denotes the total number of available common stocks in period $k-1(t)$ then the relative market share is defined as:

$$
W_{k-1(t)}^{i}=P_{k-1(t)}^{i} N_{k-1}^{i} / \sum_{i=1}^{I_{k-1(t)}} P_{k-1(t)}^{i} \times N_{k-1}^{i}
$$

where $N_{k-1}^{i}$ denotes the total number of outstanding shares at the market in period $k-1(t)$. Using the above market share as a weight we next construct the daily aggregate A.S.E. portfolio return as the value-weighted average of all individual stock returns, denoted by $R_{k(t)}$ as:

$$
R_{k(t)}=\sum_{i=1}^{I_{k(t)}} W_{k-1(t)}^{i} \times R_{k(t)}^{i}
$$

It is important that our index does not suffer from artificial changes in prices of the individual stocks since all price series have been periodically adjusted for all exogenous causes that could change them (e.g. splits etc.). In addition, our index is of higher quality than the A.S.E. Composite Share Price Index and the A.S.E. All Share Index. Although thin trading could incorporate some biases into the present index, it reflects the true available total common stock market portfolio (commonly used in asset pricing tests such as the CAPM) and it is less biased towards large stocks as is the A.S.E. Composite Share Price Index. Also, it covers a longer period of observations (almost 20 trading years) than the recently released A.S.E. All Share Index. ${ }^{4}$ Lastly, both the official A.S.E. Indexes cannot be considered to be daily, dynamic size strategies since their rebalancing takes places irregularly and few times every year as compared to our index where we rebalance the portfolio every day given the market capitalization of the previous day. ${ }^{5}$

4. In September 2004 the ASE Composite Share price Index consists only of 60 out of all stocks available, and the ASE All Stock Index has been recently constructed (May 2003). All relevant information about ASE Indexes can be found at www.ase.gr.

5. For earlier attempts in constructing a representative total market index for the ASE, see Travlos (1992) and Barkoulas, Baum and Travlos (2000). 
The value-weighted average series $R_{k(t)}$ is next used in calculating the monthly realized volatility of the A.S.E. Due to the relatively small number of trading days within the month and the proximity of the daily average return to zero, we calculate the monthly realized volatility as the monthly average of the squared returns. That is, we compute:

$$
V_{t}^{2}=\sum_{k=1}^{K(t)} R_{k(t)}^{2},
$$

where $K(t)$ denotes the total number of trading days in month $t$. In addition, we will need to compute the appropriate monthly returns; these can be immediately obtained as the cumulative return in each month $t$, that is:

$$
R_{t}=\prod_{k=1}^{K}\left(1+R_{k(t)}\right)-1
$$

For future reference, we also define the logarithmic standard deviation of the realized volatility as $L_{t}=\log \left(V_{t}\right)$ and the standardized return $Z_{t}=\left(R_{t}-\bar{R}_{t}\right) / V_{t}$, with $\bar{R}_{t}$ denoting the sample mean of the monthly returns. The total number of usable monthly observations is $T=222$. Standard descriptive statistics and statistics on the temporal characteristics of the series, which we discuss in the following section, are given in tables 1 and 2 .

\section{Properties of Realized Volatility and Returns}

\section{A. Temporal and Distributional Characteristics}

One of the prominent features of model-free measures of volatility, especially at a higher frequency of observation, is their temporal persistence. Figure 1 plots all four series used in our analysis, $V_{t}^{2}, L_{t}, R_{t}$ and $Z_{t}$. The well-documented volatility clustering can be directly observed both in the realized volatility and the log-standard deviation series. This clustering suggests that there should be a certain degree of temporal correlation in both series, with the log-standard deviation to possibly exhibit stronger correlation.

An initial gauging of the strength of serial correlation in the series is provided by the correlograms that are presented in figure 2 . The returns and the standardized returns have minimal memory, as the correlograms are within their two standard error bounds, except for the 

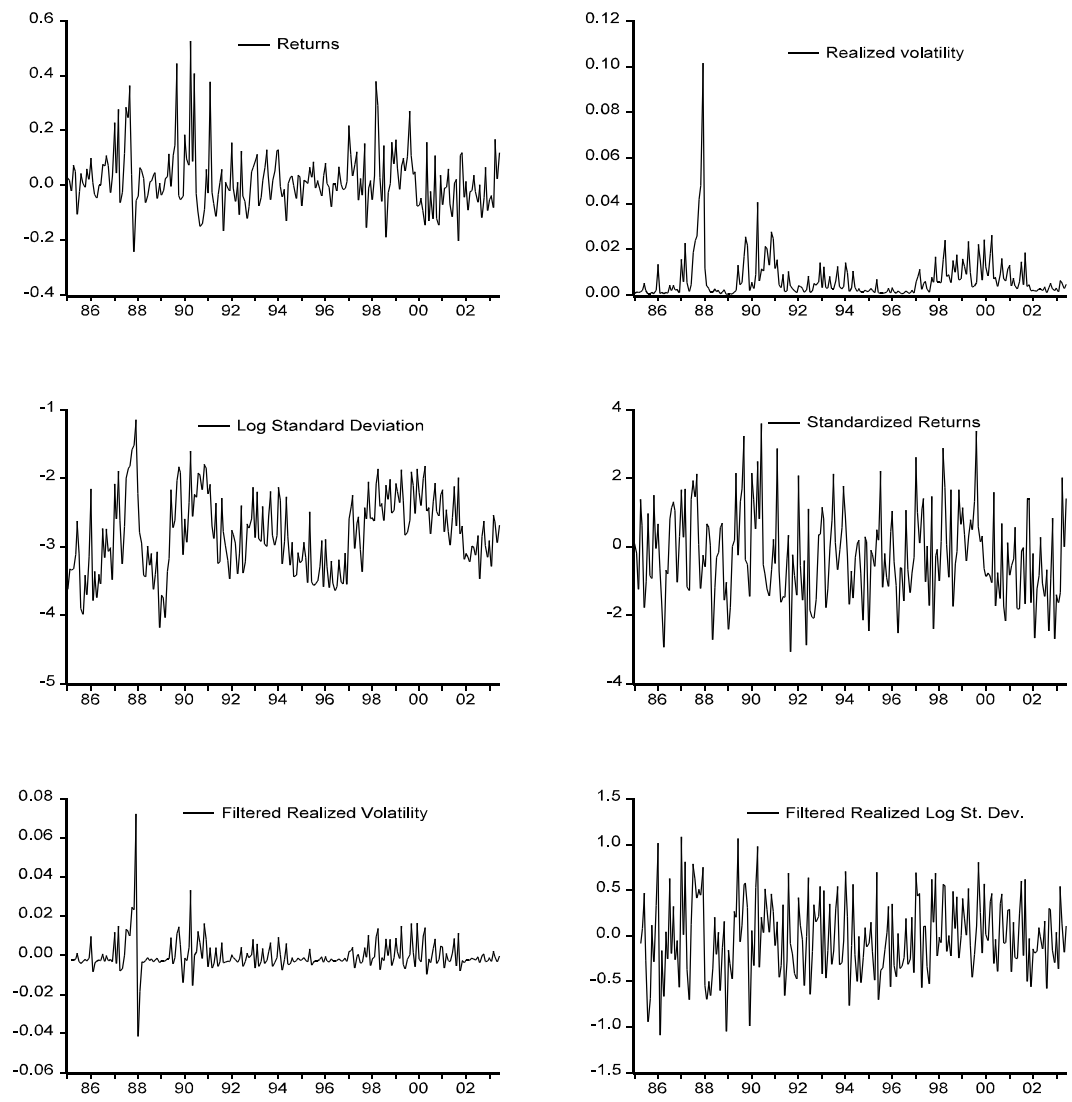

FIGURE 1.- Time Series Plots of Returns and Volatilities: 1985:1-2003:6

autocorrelation of order one. The correlograms of the realized volatility and log-standard deviation series exhibit much larger correlation: the autocorrelations of the realized volatility series drop below their two standard error bounds at about lag 5 while the corresponding autocorrelations of the log-standard deviation series do the same at about lag 10 . None of the descriptive signs of long memory can be traced in the correlograms of the two volatility series; their autocorrelations die out very fast, a clear indication of short memory. Therefore, it appears that all four series can be treated as short-memory, covariance stationary processes. ${ }^{6}$ In table 1 we present results from the

6. Also note that the sample size we have available is relatively small for computing 
Log Standard Deviation

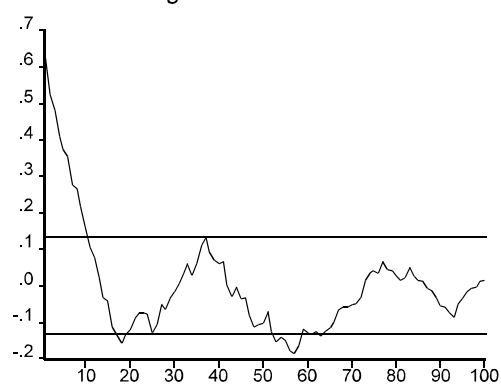

Realized Volatility

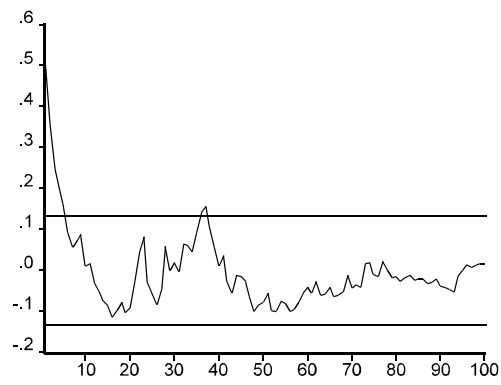

Returns

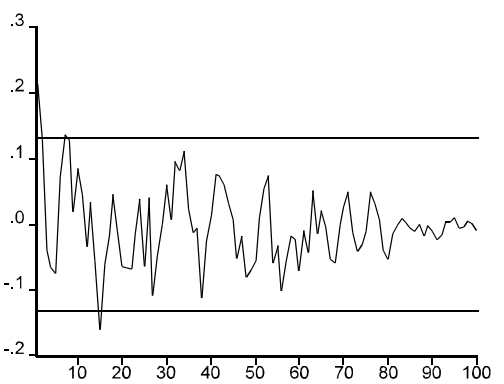

Standardized Returns

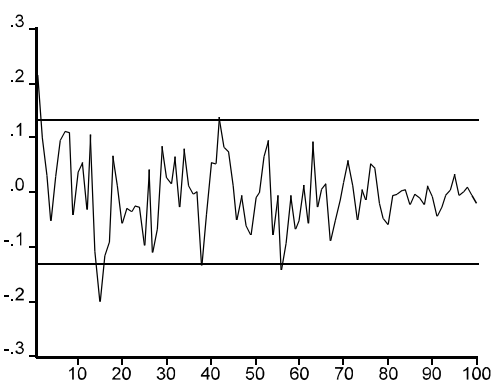

FIGURE 2.- Autocorrelation Functions: Returns and Volatilities: 1985:1-2003:6

application of the standard portmanteau test of Ljung and Box (Q -test). These Q-tests were performed for lags 5, 10, 20 and 30 and indicate the presence of various degrees of serial correlation. In agreement with the correlograms, the Q-tests show that the serial correlation is stronger in the volatility series that in the returns. For the analysis that follows we also use filtered versions of the realized volatility and log-standard deviation series, obtained from fitting autoregressive models of orders 2 and 3 respectively - estimation results are given in table $3 .{ }^{7}$ We denote

accurate estimates of the long memory parameter (fractional order) of the series.

7. In table 3 and all subsequent tables with estimation results we present also the results from (a) Chow $F$-type tests for structural stability for two breakpoints (individually and jointly) April 1995 (market liberalization/full capital mobility) and October 1999 (global peak of the ASE index), and (b) Ramsey's RESET test for functional form specification. As expected, the regression models using the realized volatility do not pass the RESET test whereas the robust regression models with the log-standard deviations do pass the test; this clearly shows the effect of the double stabilizing transformation of the square root and the 
TABLE 1. Dynamic Volatility Dependence

\begin{tabular}{|c|c|c|c|c|}
\hline Series & Q5 & Q10 & Q20 & Q30 \\
\hline$R_{t}$ & $\begin{array}{l}16.653 * * * \\
(0.005)\end{array}$ & $\begin{array}{l}27.836^{* * * *} \\
(0.001)\end{array}$ & $\begin{array}{l}38.398 * * * \\
(0.007)\end{array}$ & $\begin{array}{c}47.227 * * \\
(0.024)\end{array}$ \\
\hline$Z_{t}$ & $\begin{array}{l}13.441 * * \\
(0.020)\end{array}$ & $\begin{array}{c}21.863^{* *} \\
(0.010)\end{array}$ & $\begin{array}{l}45.106^{* *} \\
(0.001)\end{array}$ & $\begin{array}{c}55.108 * * \\
(0.003)\end{array}$ \\
\hline$V_{t}^{2}$ & $\begin{array}{r}112.74 * * \\
(0.000)\end{array}$ & $\begin{array}{r}118.46^{* * *} \\
(0.000)\end{array}$ & $\begin{array}{r}134.51 * * \\
(0.000)\end{array}$ & $\begin{array}{r}141.25^{* *} \\
(0.000)\end{array}$ \\
\hline$L_{t}$ & $\begin{array}{c}272.56 * * \\
(0.000)\end{array}$ & $\begin{array}{c}352.11 * * \\
(0.000)\end{array}$ & $\begin{array}{c}378.84 * * \\
(0.000)\end{array}$ & $\begin{array}{c}394.59 * * \\
(0.000)\end{array}$ \\
\hline
\end{tabular}

Note: The table reports sample (1985:1-2003:6) Ljung-Box statistics $\left(Q_{k}\right.$, for $k=$ $5,10,20,30$ lags) for autocorrelation for the various measures of returns and volatility. $R_{t}, Z_{t}$ $V_{t}^{2}$ and $L_{t}$ denotes returns, standardized returns, realized volatility and logarithmic standard deviation respectively. $* * *$ and $* * *$ denote significance at $10 \%, 5 \%$ and $1 \%$ respectively and $p$-values appear in parentheses.

these two series by $V_{t}^{f}$ and $L_{t}^{f}$. With the filtered (residual) series we can work with the non-predictable (from its own past) component of realized volatility.

In table 2 we present descriptive and distributional statistics for all six series, that is including the filtered versions noted above. Given that the series appear to only have short (or no) memory, we can use standard distributional tests to examine whether they conform to an underlying Gaussian distribution. We use two distributional tests for assessing normality, the sample moments-based test of Jarque and Bera (1982) and the sample quantiles-based Crámer-Von Mises test. The tests are in agreement that, as expected, the returns and the realized volatility series have large deviations from normality while the standardized returns and the log-standard deviation series (including the filtered series $L_{t}^{f}$ ) appear to be coming from an underlying Gaussian distribution. In the next session, where we present our results for the linkages between volatility and returns, we mainly use the log-standard deviation as our measure of volatility.

Summarizing, our findings appear to be consistent with the rest of the literature: nearly uncorrelated and non-normal returns, serially correlated and non-normal realized volatility, serially correlated and normal realized log-standard deviation and normal standardized returns.

logarithm. 
TABLE 2. Descriptive Statistics of Returns and Volatilities

\begin{tabular}{|c|c|c|c|c|c|c|}
\hline Statistics & $R_{t}$ & $V_{t}^{2}$ & $L_{t}$ & $Z_{t}$ & $V_{t}^{f}$ & $L_{t}^{f}$ \\
\hline Mean & 0.0235 & 0.0072 & -2.7747 & -0.1742 & $1.14 \mathrm{E}-05$ & $2.16 \mathrm{E}-16$ \\
\hline Median & 0.0093 & 0.0037 & -2.7937 & -0.2504 & -0.0022 & -0.0182 \\
\hline Max. & 0.5257 & 0.1016 & -1.1435 & 3.5955 & 0.0721 & 1.0816 \\
\hline Min. & -0.2435 & 0.0002 & -4.1789 & -3.0763 & -0.0416 & -1.0936 \\
\hline Std. Dev. & 0.1104 & 0.0100 & 0.5603 & 1.3236 & 0.0086 & 0.4217 \\
\hline Skewness & 1.3315 & 4.7792 & 0.0848 & 0.2937 & 2.8286 & 0.1147 \\
\hline Kurtosis & 6.5710 & 39.283 & 2.4771 & 2.7816 & 27.569 & 2.6804 \\
\hline $\mathrm{J}-\mathrm{B}$ & 181.073 & 12846.210 & 2.758 & 3.583 & 5799.988 & 1.413 \\
\hline ( $p$-value) & 0.0000 & 0.0000 & 0.2519 & 0.1667 & 0.0000 & 0.4935 \\
\hline $\begin{array}{l}\text { CVM } \\
\text { ( } p \text {-value) }\end{array}$ & $\begin{array}{l}0.738^{* * *} \\
(0.000)\end{array}$ & $\begin{array}{l}3.971 * * * \\
(0.000)\end{array}$ & $\begin{array}{c}0.092 \\
(0.142)\end{array}$ & $\begin{array}{c}0.079 \\
(0.209)\end{array}$ & $\begin{array}{l}3.304 * * * \\
(0.000)\end{array}$ & $\begin{array}{c}0.085 \\
(0.177)\end{array}$ \\
\hline
\end{tabular}

Note: The table reports sample (1985:1-2003:6) statistics for the various measures of returns and volatility. $R_{t}, V_{t}^{2}, L_{t}, Z_{t}, V_{t}^{f}$ and $L_{t}^{f}$ denote returns, realized volatility, logarithmic standard deviation, standardized returns and the residuals from the autoregressive model for realized standard deviation and logarithmic standard deviation respectively. J-B and CVM denote the Jarque-Bera and Crámer-Von Mises normality tests respectively. *, ** and $* * *$ denote significance at $10 \%, 5 \%$ and $1 \%$ respectively.

The only difference with the recent realized volatility difference is the lower degree of temporal dependence that we find in the realized volatility series: our series have short rather than long memory.

\section{B. Tests on Asymmetric Volatility}

This section empirically examines the asymmetric relationship between future logarithmic realized standard deviation and past standardized A.S.E. market returns and past log realized volatility from February 1985 to June 2003. In order to identify the channels of asymmetry between risk and return and the asymmetries in temporal dependencies in volatility we start by estimating simple regressions gauging the, so-called, volatility feedback effect - that is, the contemporaneous relationship between risk and return. The volatility feedback regressions take the same form as in Bollerslev and Zhou (2006), that is:

$$
R_{t}=a+\beta X_{t}+u_{t},
$$

for the various realized risk measures $X_{t}$ described in the previous section, namely the realized volatility $V_{t}^{2}$, the realized standard 
deviation $V_{t}$, the logarithmic standard deviation $L_{t}$, the filtered realized volatility $V_{t}^{f}$ and the filtered realized $\log$ standard deviation $L_{t}^{f}$. The results on the volatility feedback effect are given in table 4 and are all consistent with the potential presence of some positive feedback between realized risk and returns: while the regression fit is less than $5 \%$ in all five cases, the estimated coefficients appear to be statistically significant. The positive signs from these regressions are what is conventionally found and anticipated. Note that all the regressions except for the first (realized volatility) and the last (filtered log-standard deviation) pass the RESET test for functional form specification as well as the breakpoint test for April 1994, while they fail (as one would expect) to pass the breakpoint test for October 1999 where we have the global peak of the index.

In examining the possible presence of leverage in our data we employ the following generic regression:

$$
a(B) v_{t}=a_{0}+\beta r_{t-1}+\gamma r_{t-1} \cdot i r_{t\left(r_{t-1}<0\right)}+u_{t}
$$

where $v_{t}$ stands for any of the four measures of realized volatility $V_{t}^{2}, L_{t}, V_{t}^{f}, L_{t}^{f}, r_{t}$ stands for any of the two measures of returns $R_{t}$ or $Z_{t}$, $a(B)$ is an autoregressive polynomial of degree 0 (if $v_{t}=V_{t}^{f}$ or $L_{t}^{f}$ ), 2 (if $v_{t}=V_{t}^{2}$ ) or 3 (if $v_{t}=L_{t}$ ), where $B$ is the backward shift operator $B^{j}$ $x_{t}=x_{t-j}, i r_{t}$ stands for the indicator function that takes the value of one when past period's returns (as defined by $r_{t}$ ) are negative and the coefficients $\beta$ and $\gamma$ measure the possible presence of a leverage/ asymmetric effect: such a presence is related to an ex-ante anticipation for a parametric inequalities of the form $\beta+\gamma<0$ and $\beta<|\gamma|$. The tables with the results also include a Wald-type test for the null hypothesis $H_{0}$ : $\beta+\gamma=0$.

Our results for these leverage effect regressions are give in tables 5 and 6 . The estimation results are statistically robust and economically consistent with the presence of strong asymmetries between risk and return in the A.S.E. market. The inclusion of lagged returns and their asymmetry indicator does not really affect the strong positive relationship between past and current risk - note that the estimates of the $a(B)$ parameters do not really change with respect to the corresponding estimates in table 3 and all remain significant. In six out of eight possible regressions (using all measures of risk and return noted above) we find statistically significant estimates for the leverage parameters $\beta$ and $\gamma$ with the anticipated signs and relative magnitudes. In four out of these eight possible regressions we also find that the leverage estimates for $\gamma$ are not only negative and larger (in absolute value) than the 


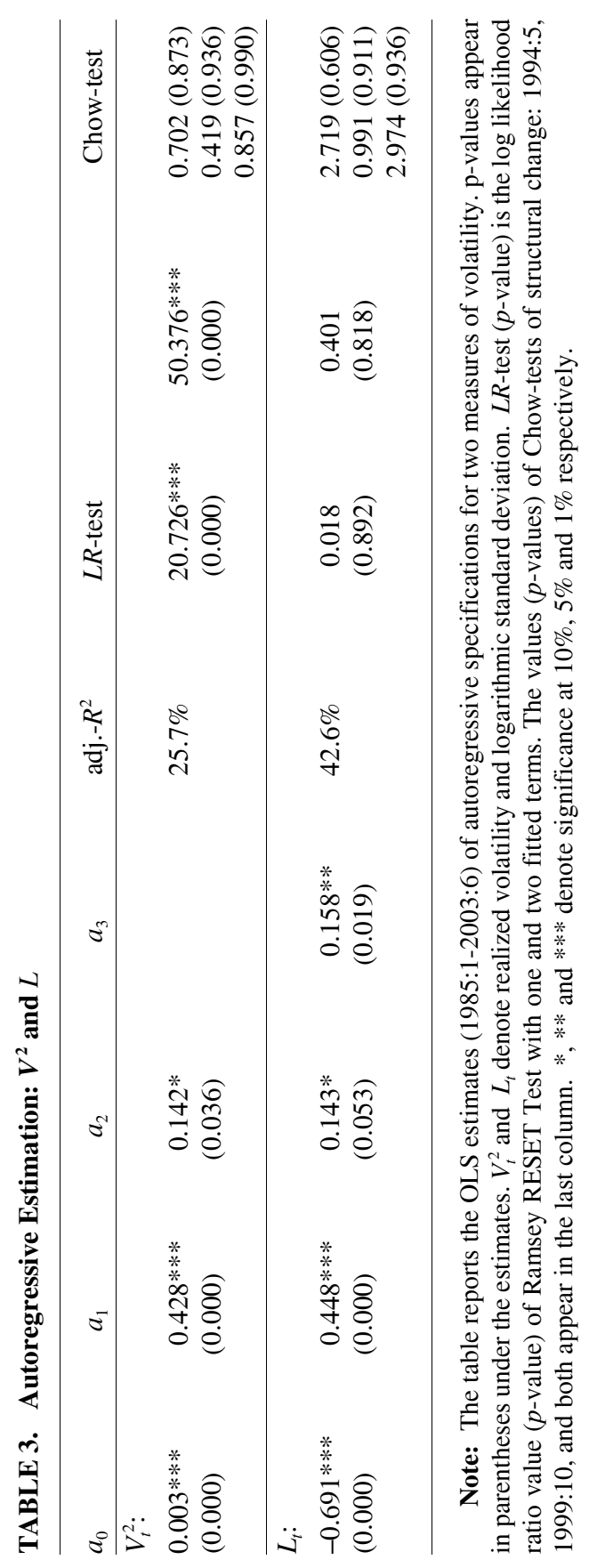




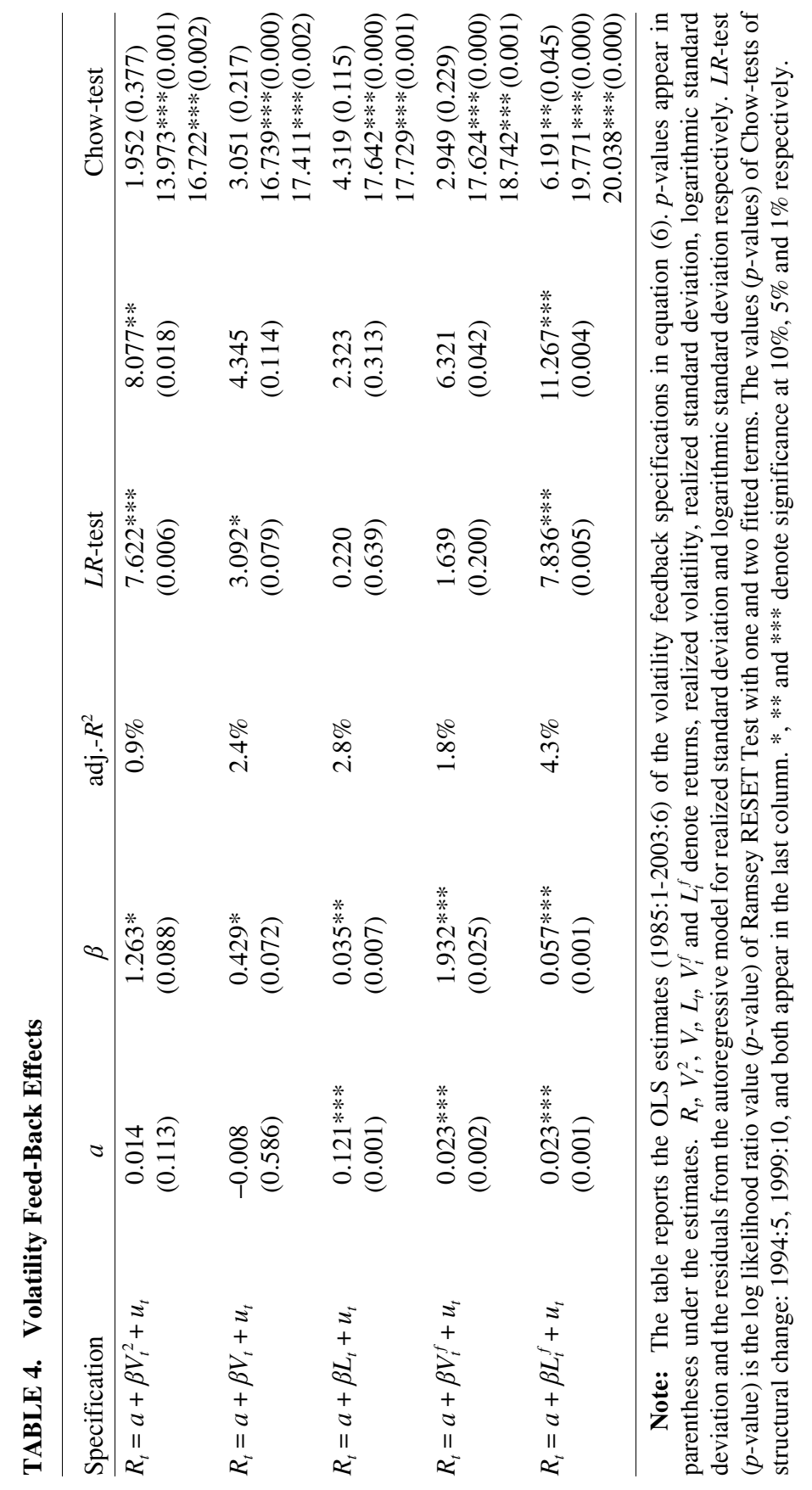




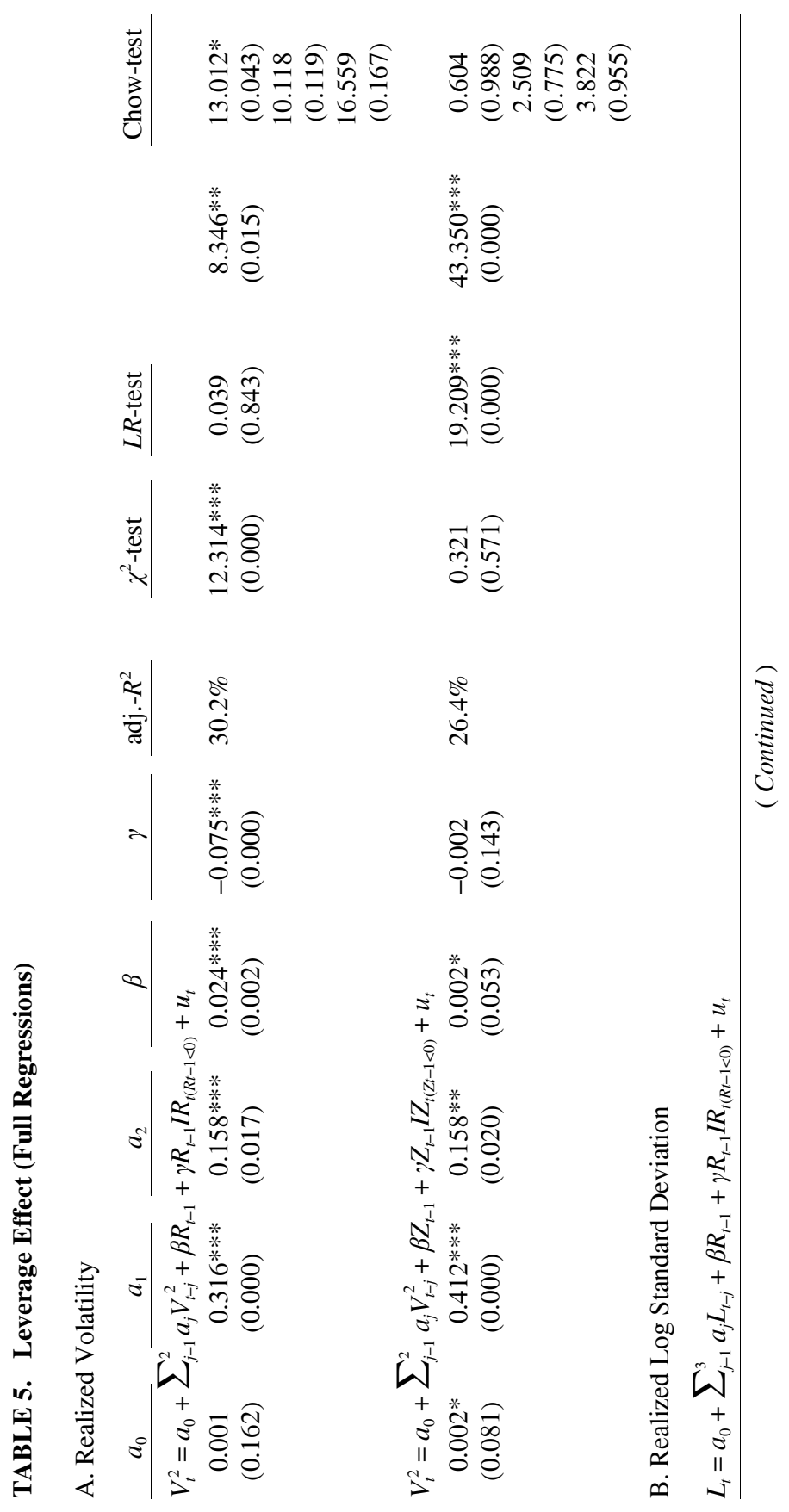




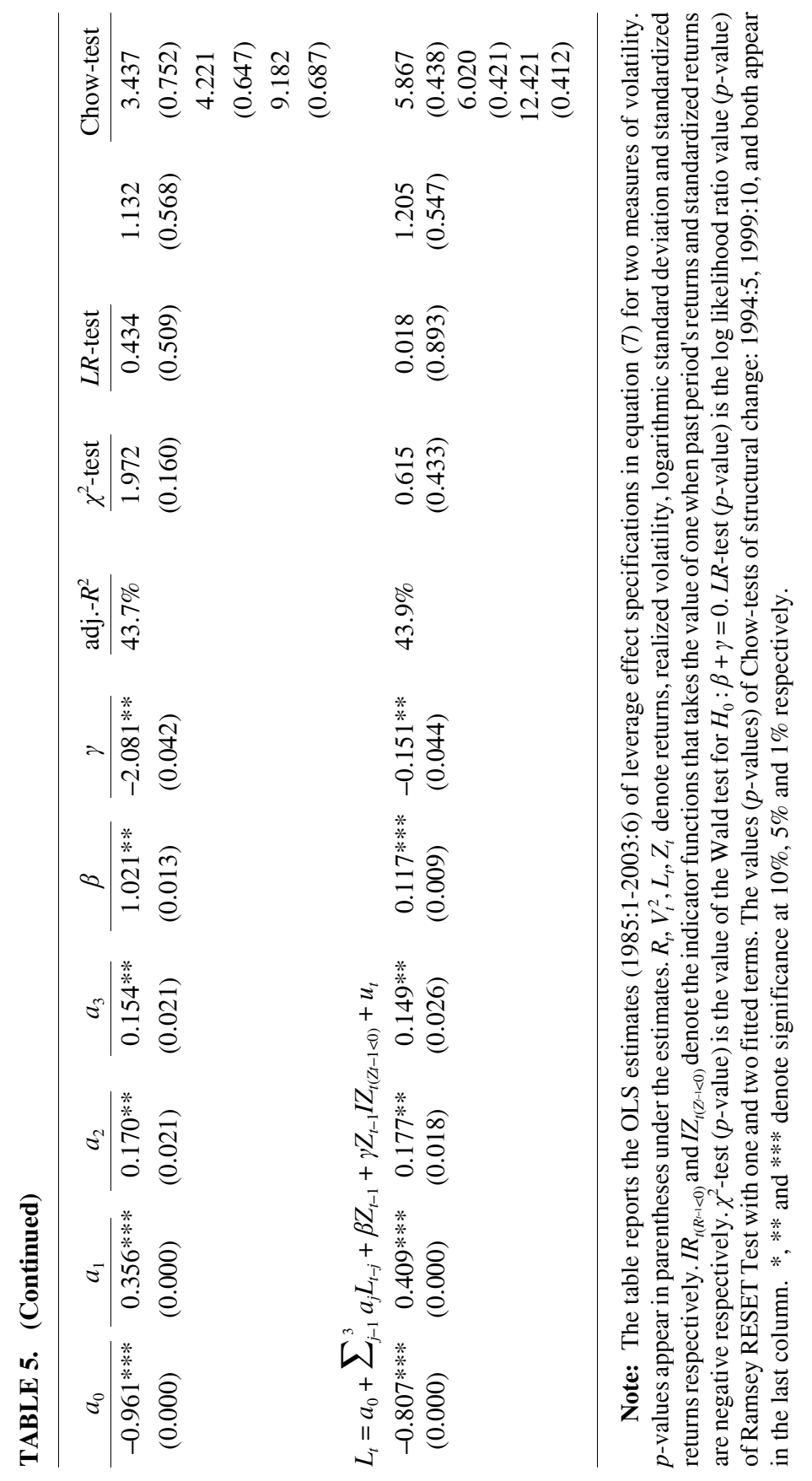




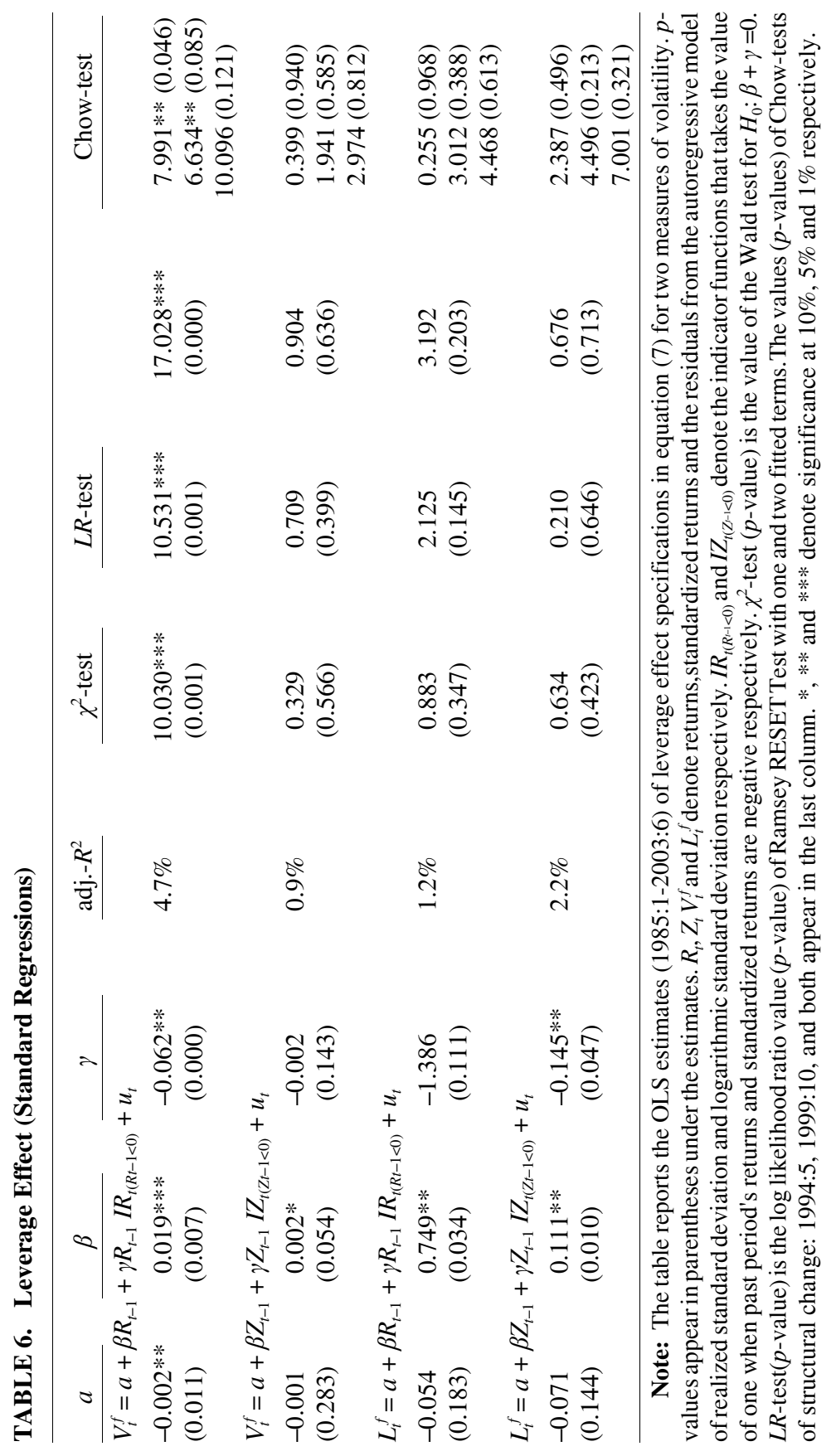


estimates for $\beta$ but also that the estimates for $\beta+\gamma$ (measuring the total effect of negative returns) were larger than the estimates for $\beta$ alone (measuring the effect of positive returns). We note that it appears that the use of the standardized returns clouds the presence of the leverage effect: the regressions using the (simple) returns reveal the leverage effect much more strongly. Finally, it appears that almost all specifications are well specified, as they pass both the RESET specification test and the Chow tests for three different break periods.

The interpretation of these results is actually quite interesting, when viewed in the context of a small and relatively inefficient market as the A.S.E.: negative lagged returns imply a stronger and negative response of current volatility, when compared to the weaker and positive response of current volatility to positive lagged returns. Let us consider as an example one of the estimated regressions, the regression of realized volatility on past returns in table 5 (Panel A): the response estimate for positive returns is 0.024 while the response estimate for negative returns is $0.024-0.075=-0.051$. This implies that a $1 \%$ increase in the monthly A.S.E. returns will increase average monthly volatility by 0.024 when the market keeps rising; on the other hand, a $1 \%$ reduction in the returns will increase average monthly volatility by 0.051 when the market keeps falling.

The combined results from the volatility feedback regressions and the leverage regressions are strong indications that the A.S.E. market behaves like a textbook case, following well-established financial rules: not only there is strong evidence of financial leverage, but there appears that the A.S.E. market has a time-varying risk premium that is an increasing function of volatility; that premium increases with an anticipated increase in volatility thus raising the anticipated return on equity, which in turn implies an immediate decline on equity price. Could these results imply that our realized volatility measure could be used as a significantly priced factor in the A.S.E. returns? If yes, how would this result compare with the related existing literature? We explore these questions in the following section.

\section{Realized Market Volatility as a Priced Risk Factor}

Time-varying aggregate realized market volatility implies temporal changes in the set of future investment opportunities for any rational long-term investor (Chen (2003), Ang, Hodrick, Xing and Zhang (2006) and Guo and Whitelaw (2006)). As such, the co-movement of asset 
returns with aggregate market volatility should carry significant risk premia. In this section we turn in examining whether contemporaneous and long-term measured market realized risk could be a priced factor in the cross-section of A.S.E. common stock portfolio returns. In an unconditional multi-factor asset pricing framework similar to Merton (1973) and Campbell (1996) we ask whether realized volatility is such a factor and as a result whether differences in the unconditional premia across A.S.E. portfolios should be related to differences in portfolios' unconditional exposures to aggregate market volatility. Although, several asset pricing studies have been performed using A.S.E. data, none of these examines the pricing ability of realized market risk.

In order to establish an empirical link between portfolio risk premia and aggregate realized volatility $V_{t}^{2}$ and realized logarithmic standard deviation $L_{t}$ respectively, we implement a standard asset pricing model with a beta-premium representation, where asset betas (loadings) with different measures of realized risk serve as competing factors in the cross-section of average excess returns on stock portfolios from the A.S.E.:

$$
E\left[R_{i}^{e}\right]=\gamma_{0}+\gamma_{m} \beta_{i m}+\gamma_{V O L} \beta_{i V O L}+\gamma_{S M B} \beta_{i S M B}+\gamma_{H M L} \beta_{i H M L},
$$

where $R_{i, t}^{e}=R_{i, t}-R_{f, t}$ is the simple excess return on asset $i, \beta$ 's are the portfolios' factor loadings (betas), SMB (Small-Minus-Big) and $H M L$ (High-Minus-Low) are the two Fama-French (1993) size and book-to-market related factor mimicking portfolios, respectively, $V O L_{t}$ is the aggregate realized volatility factor $V O L_{t}=V_{t}^{2}$ or $L_{t}, \gamma^{\prime} \mathrm{s}$ are the prices of beta risk and, finally, $\gamma_{0}$ is the pricing error, that is the difference between actual and model-implied average returns.

The Fama-French portfolios $S M B$ and $H M L$ have been extensively used as systematic risk factors, both in domestic and international asset pricing studies, and show considerable success in pricing alternative classes of assets (see, among others, Fama and French (1993, 1996, 1997), Griffin (2001) and Petkova (2006)). Both factors represent the returns on zero-cost investments that go long and short in common stocks that differ according to market capitalization (size) and book-to-market. More specifically, SMB is the return on a portfolio that invests one monetary unit in small-cap stocks while goes short one monetary unit in large-cap stocks. Similarly, $H M L$ is the return differential between two portfolios consisting of high (value) and low (growth) book-to-market stocks, respectively. Fama and French argue that the returns on these zero-cost portfolios mimic sources of 
systematic economic risk, like distress and profitability, and, as such, are able to describe the time-series and cross-section of expected returns through a purely rational asset pricing model. Although, still, there is an ongoing debate of whether the returns on these portfolios represent economy-wide factors or not, the empirical success of the model is rarely questioned, at least in its unconditional form, and this is the reason why the two factors are included in our asset pricing tests. ${ }^{8}$

The linear relationship between aggregate realized market risk and average portfolio returns in (8) is empirically examined using the three-step Fama-MacBeth (1973) methodology. In the first step, and for each portfolio $i=1, \ldots, N$, the unconditional factor loadings are estimated from time-series regressions of simple realized portfolio returns $R_{i, t}$ on market return $R_{m, t}$, realized market risk $V O L_{t}$ (either realized market variance $V_{t}^{2}$ and realized logarithmic market standard deviation $L_{t}$ ) and the returns on the two Fama-French (1993) zero-cost size and value mimicking portfolios $S M B_{t}$ and $H M L_{t}$, respectively:

$$
\begin{aligned}
R_{i, t}= & a_{0}+\beta_{i m} R_{m, t}+\beta_{i V O L} V O L_{t}+\beta_{i S M B} S M B_{t}+\beta_{i H M L} H M L_{t}+u_{i, t} ; \\
& \forall i=1, \ldots, N
\end{aligned}
$$

In the second step, the unconditional prices of beta risk $\gamma$ 's are estimated by running a set monthly $t=1, \ldots, T$ cross-sectional OLS regressions of realized portfolio excess returns $R_{t}^{e}$ on the estimated beta risks:

$$
\begin{aligned}
R_{t}^{e}= & \gamma_{0}+\gamma_{m} \widehat{\beta}_{i m}+\gamma_{V O L} \widehat{\beta}_{i V O L}+\gamma_{S M B} \widehat{\beta}_{i S M B}+\gamma_{H M L} \widehat{\beta}_{i H M L}+e_{t} \\
& \forall t=1, \ldots, T
\end{aligned}
$$

The above cross-sectional asset pricing equation is estimated using betas with both contemporaneous and long-term (60-day, 120-day and 240-day $V^{2}$ and $L$ ) realized market volatilities. ${ }^{9}$ In the final step, the Fama-MacBeth methodology estimates and infers about the beta prices

8. For example, Petkova (2006) shows that the two factors are strongly correlated with innovations in variables that describe the set of future investment opportunities. Furthermore, Liew and Vassalou (2000) presents evidence that $H M L$ and $S M B$ have forecasting ability over future economic growth in several countries and as such she provides support to a rational, risk-based explanation of the empirical performance of the two portfolios as priced risk factors. On the other hand Daniel and Titman (1997), and Daniel, Titman and Wei (2001) provide evidence in favor to a characteristics (rather than a risk) model.

9. The long-term realized volatilities were computed using the corresponding rolling sample squared returns. 
of risk $\gamma \mathrm{s}$ and the pricing error term $\left(\gamma_{0}\right.$, the difference between the actual and fitted values in (10)) using the time-series estimates of the cross-sectional regression estimates, that is $\hat{\gamma}_{k}=(1 / T) \sum_{t=1}^{T} \hat{\gamma}_{k, t}$ and $s^{2}\left(\hat{\gamma}_{k}\right)=(1 / T) \sum_{t=1}^{T}\left(\hat{\gamma}_{k, t}-\hat{\gamma}_{k}\right)^{2}$, for $k=m, V O L, S M B$ and $H M L$, respectively. The presence of pre-estimated betas as explanatory variables in the cross-sectional regressions in (10) generates an EIV problem which leads to low (high) standard errors ( -statistics). Following the advice of Shanken (1992) we correct for the fact that betas were estimated with error from the first-step regression in (9). If we denote by $\hat{\Gamma}=\left(\hat{\gamma}_{0}, \hat{\gamma}_{m}, \hat{\gamma}_{V O L}, \hat{\gamma}_{S M B}, \hat{\gamma}_{H M L}\right)^{\prime}$ the vector of estimated risk premia, $\Omega_{k}$ the sample covariance matrix of risk factors and $s_{k}^{2}$ the variance of the mean of the $k^{\text {th }}$ factor (i.e. $R_{m}, V O L, S M B$ or $H M L$ ), the EIV-adjusted standard errors of the sample mean of risk premia are calculated as the square root of $\left(s^{2}\left(\hat{\gamma}_{k}\right)-s_{k}^{2}\right)(1+c)+s_{k}^{2}$, where $c=\Gamma^{\prime} \Omega_{k}^{-1} \hat{\Gamma}$ (see, Shanken and Weinstein (2006)). Lastly, we use the time-series average adjusted- $R^{2}$ from the cross-sectional regressions in (10) $\left(\right.$ adj. $-R^{2}=(1 / T) \sum_{t=1}^{T}$ adj. $\left.R_{t}^{2}\right)$ as an intuitive measure of the cross-sectional fit. Although, the success of any cross-sectional model cannot be judged on the values of this metric, we report it to facilitate the comparison of our results with those in the existing literature in cross-sectional asset pricing tests.

\section{A. Portfolio Construction}

In what follows we use monthly observations from A.S.E. and we employ a variant of the Fama and French (1993) methodology to construct returns on 25 firm-characteristic single-sorted portfolios on book-to-market, size, dividend-yield, price-earnings and 3-month momentum, and the two Fama and French (1993) size and book-to-market factor mimicking portfolios, Small-Minus-Big (SMB) and High-Minus-Low $(H M L)$ respectively. The formation process of the test portfolios slightly differs from Fama and French (1993) and closely follows Lewellen (1999) in the sense that we construct monthly dynamic investment strategies where portfolio rebalancing takes place at the beginning of each month using the most current history of portfolio returns and asset characteristics. ${ }^{10}$

10. We have also estimated the beta prices of risk using portfolio returns employing a 6-month rebalancing. However, there are no important quantitative differences in our results. 
The 25 portfolios were constructed using last month's accounting and financial data. First, we break the full menu of A.S.E. common stocks available at any given month $t$ into 5 groups (based on accounting information) each containing an equal number of stocks and second, we compute the simple market capitalization weighted-average monthly holding period return for each of the 5 portfolios from $t$ to $t+1$. The procedure is repeated every month from July 1991 to June 2003 and we end up with time-series data of simple returns on each characteristics-sorted portfolio. For the construction of excess returns we use the average T-bill rate.

In order to construct the value factor portfolio $H M L$ we use the standard Fama-French (1993) $30 \%$ (Low)-40\%( Medium)-30\%( High) book-to-market breakpoint rule. However, for the $S M B$ portfolio, we adjust the formation mechanism to account for peculiarities of the Greek data. We use the 70th quantile of the market capitalization instead of the median that was introduced by Fama and French. ${ }^{11}$ Using a larger breakpoint we can create a distribution of the market value similar to that of Fama and French, while the small capitalization portfolio represents on average the $8 \%$ of the total A.S.E. market. The risk factor portfolio construction has as follows. At the end of June of each year all available stocks are independently sorted into 3 groups according to their past book-to-market value and 2 groups according to their past market capitalization. Then, we construct six portfolios $S L, S M, S H, B L$, $B M$ and $B H$ from the intersections of the three book-to-market and the two size groups. For example, the $\mathrm{SH}$ portfolio consists of stocks that belong to the smallest size and highest book-to-market groups respectively. Then, we calculate the value-weighted monthly returns for the next 12 months. Finally, the returns on the aggregate book-to-market and size portfolios are defined as the return differential between the extreme high-low and small-large portfolios $H M L=$ $(S H+B H) / 2-(S L+B L) / 2$ and $S M B=(S L+S M+S H) / 3-(B L+B M+B H) / 3$, respectively.

Our choice of sample and use of sorted portfolios of groups of five, rather than individual stocks, needs some further justification. First, we want to examine whether the realized volatility factor can explain differences in characteristics-based portfolio returns that are well documented in the literature. ${ }^{12}$ Second, the small number of available

\footnotetext{
11. See, Dimson, Nagel and Quigley (2003) for a similar sorting approach using UK data.

12. See, for example, Banz (1981) and Fama and French (1996) for the "size effect",
} 
TABLE 7. Statistics of Test and Risk Factor Portfolios

A. B/M Portfolios

\begin{tabular}{|c|c|c|c|c|c|}
\hline & High & 2 & 3 & 4 & Low \\
\hline Mean & 0.0211 & 0.0141 & 0.0073 & 0.0067 & 0.0111 \\
\hline Median & 0.0008 & -0.0049 & -0.0007 & 0.0088 & 0.0051 \\
\hline Maximum & 0.3987 & 0.44 & 0.3366 & 0.4052 & 0.3922 \\
\hline Minimum & -0.2948 & -0.2181 & -0.1938 & -0.2573 & -0.2025 \\
\hline Std.Dev. & 0.1176 & 0.1052 & 0.0994 & 0.0967 & 0.0958 \\
\hline Skewness & 0.7933 & 0.9791 & 0.6255 & 0.5175 & 0.6906 \\
\hline Kurtosis & 4.2631 & 4.6063 & 3.6971 & 4.9967 & 5.1804 \\
\hline $\begin{array}{l}\mathrm{J} \text {-B test } \\
(p \text {-value })\end{array}$ & $\begin{array}{l}24.7 \\
(0.0000)\end{array}$ & $\begin{array}{l}38.5 \\
(0.0000)\end{array}$ & $\begin{array}{l}12.3 \\
(0.0021)\end{array}$ & $\begin{array}{l}30.3 \\
(0.0000)\end{array}$ & $\begin{array}{l}39.9 \\
(0.0000)\end{array}$ \\
\hline
\end{tabular}

B. Size Portfolios

\begin{tabular}{|c|c|c|c|c|c|}
\hline & Large & 2 & 3 & 4 & Small \\
\hline Mean & 0.0109 & 0.0105 & 0.0147 & 0.0241 & 0.0348 \\
\hline Median & 0.0101 & 0.0039 & 0.0006 & 0.0031 & 0.0034 \\
\hline Maximum & 0.4294 & 0.453 & 0.5907 & 0.5147 & 0.5998 \\
\hline Minimum & -0.1976 & -0.2762 & -0.2758 & -0.293 & -0.3073 \\
\hline Std.Dev. & 0.0904 & 0.1079 & 0.1226 & 0.1333 & 0.1535 \\
\hline Skewness & 0.8296 & 0.6555 & 0.9461 & 0.8805 & 1.2641 \\
\hline Kurtosis & 5.8419 & 4.637 & 5.8077 & 4.891 & 5.457 \\
\hline $\begin{array}{l}\mathrm{J}-\mathrm{B} \text { test } \\
(p \text {-value })\end{array}$ & $\begin{array}{l}64.9 \\
(0.0000)\end{array}$ & $\begin{array}{l}26.4 \\
(0.0000)\end{array}$ & $\begin{array}{l}68.8 \\
(0.0000)\end{array}$ & $\begin{array}{l}40.1 \\
(0.0000)\end{array}$ & $\begin{array}{l}74.6 \\
(0.0000)\end{array}$ \\
\hline
\end{tabular}

C. DY Portfolios

\begin{tabular}{|c|c|c|c|c|c|}
\hline & High & 2 & 3 & 4 & Low \\
\hline Mean & 0.0188 & 0.0118 & 0.0085 & 0.0121 & 0.0052 \\
\hline Median & 0.0099 & 0.0048 & 0.0047 & 0.0064 & 0.0006 \\
\hline Maximum & 0.3955 & 0.5391 & 0.3482 & 0.4214 & 0.374 \\
\hline Minimum & -0.1659 & -0.2721 & -0.234 & -0.2304 & -0.1998 \\
\hline Std.Dev. & 0.0965 & 0.1066 & 0.0975 & 0.1037 & 0.1016 \\
\hline Skewness & 0.8163 & 1.0391 & 0.5244 & 0.5621 & 0.5472 \\
\hline Kurtosis & 4.6283 & 6.448 & 3.8114 & 5.0566 & 4.0808 \\
\hline $\begin{array}{l}\mathrm{J}-\mathrm{B} \text { test } \\
(p \text {-value })\end{array}$ & $\begin{array}{l}31.9 \\
(0.0000)\end{array}$ & $\begin{array}{l}97.2 \\
(0.0000)\end{array}$ & $\begin{array}{l}10.5 \\
(0.0051)\end{array}$ & $\begin{array}{l}32.9 \\
(0.0000)\end{array}$ & $\begin{array}{l}14.2 \\
(0.0008)\end{array}$ \\
\hline
\end{tabular}

( Continued)

Lakonishok, Shleifer and Vishny (2004), and Campbell, Polk and Vuolteenaho (2007) for the "value effect", Basu (1977) and Fama and French (1993) for the "price-earnings" effect, and Jegadeesh and Titman (1993) for the "momentum" effect. 
TABLE 7. (Continued)

D. P/E Portfolios

\begin{tabular}{|c|c|c|c|c|c|}
\hline & High & 2 & 3 & 4 & Low \\
\hline Mean & 0.0079 & 0.0081 & 0.0091 & 0.0125 & 0.0225 \\
\hline Median & 0.0017 & 0.0091 & -0.0015 & 0.0029 & 0.0139 \\
\hline Maximum & 0.4526 & 0.3915 & 0.4031 & 0.2869 & 0.3518 \\
\hline Minimum & -0.2556 & -0.2032 & -0.2526 & -0.2197 & -0.1558 \\
\hline Std.Dev. & 0.1167 & 0.1004 & 0.0967 & 0.0881 & 0.0988 \\
\hline Skewness & 0.9835 & 0.4218 & 0.723 & 0.4778 & 0.769 \\
\hline Kurtosis & 5.6917 & 3.9484 & 5.3587 & 3.6723 & 3.5172 \\
\hline $\begin{array}{l}\mathrm{J}-\mathrm{B} \text { test } \\
(p \text {-value })\end{array}$ & $\begin{array}{l}66.7 \\
(0.0000)\end{array}$ & $\begin{array}{l}9.7 \\
(0.0000)\end{array}$ & $\begin{array}{l}45.9 \\
(0.0000)\end{array}$ & $\begin{array}{l}8.2 \\
(0.0167)\end{array}$ & $\begin{array}{l}15.8 \\
(0.0004)\end{array}$ \\
\hline
\end{tabular}

F. 3-Month Momentum Portfolios

\begin{tabular}{|c|c|c|c|c|c|}
\hline & Winners & 2 & 3 & 4 & Losers \\
\hline Mean & 0.0141 & 0.0156 & 0.0094 & 0.0084 & 0.0024 \\
\hline Median & 0.008 & 0.0082 & 0.0009 & 0.0026 & 0.0039 \\
\hline Maximum & 0.5382 & 0.5345 & 0.5311 & 0.4734 & 0.4277 \\
\hline Minimum & -0.2185 & -0.2264 & -0.2736 & -0.2902 & -0.3381 \\
\hline Std.Dev. & 0.1097 & 0.109 & 0.1056 & 0.1055 & 0.1184 \\
\hline Skewness & 1.0266 & 1.098 & 0.8987 & 0.9943 & 0.3549 \\
\hline Kurtosis & 6.6308 & 6.8301 & 6.538 & 5.7125 & 4.257 \\
\hline $\begin{array}{l}\mathrm{J}-\mathrm{B} \text { test } \\
(p \text {-value })\end{array}$ & $\begin{array}{l}104.4 \\
(0.0000)\end{array}$ & $\begin{array}{l}116.9 \\
(0.0000)\end{array}$ & $\begin{array}{l}94.5 \\
(0.0000)\end{array}$ & $\begin{array}{l}67.9 \\
(0.0000)\end{array}$ & $\begin{array}{l}12.5 \\
(0.0019)\end{array}$ \\
\hline
\end{tabular}

G. Fama-French Risk Factor Portfolios

\begin{tabular}{lcc} 
& $S M B$ & $H M L$ \\
\cline { 2 - 2 } Mean & 0.0118 & 0.006 \\
Median & -0.0031 & 0.0071 \\
Maximum & 0.327 & 0.2851 \\
Minimum & -0.2636 & -0.2776 \\
Std.Dev. & 0.0789 & 0.0749 \\
Skewness & 0.7866 & -0.0914 \\
Kurtosis & 5.7579 & 6.4002 \\
J-B test & 65.5 & 75.7 \\
$(p$-value $)$ & $(0.0000)$ & $(0.0000)$ \\
\hline
\end{tabular}

Note: The table reports sample (1991:7-2003:6) statistics for the 25 test portfolios (book-to-market $(B / M)$, size, dividend-yield $(D Y)$, price-earnings $(P / E)$ and 3 month momentum) and the Fama-French (1993) zero-cost factor mimicking portfolios $S M B$ and $H M L$. J-B denotes the Jarque-Bera normality test. 
TABLE 8. Sample Correlation Matrix of Risk Factors

\begin{tabular}{lrrr}
\hline & $R_{m}$ & $H M L$ & $S M B$ \\
\hline$H M L$ & -0.084 & & \\
$S M B$ & -0.017 & 0.229 & \\
$V^{2}$ & 0.044 & -0.179 & -0.023 \\
$V_{60}^{2}$ & 0.002 & -0.169 & 0.166 \\
$V_{120}^{2}$ & 0.004 & -0.117 & 0.169 \\
$V_{240}^{2}$ & -0.055 & -0.064 & 0.168 \\
$L^{2}$ & 0.078 & -0.142 & 0.052 \\
$L_{60}$ & 0.039 & -0.125 & 0.186 \\
$L_{120}$ & -0.068 & 0.193 \\
$L_{240}$ & 0.025 & -0.049 & 0.199 \\
\hline
\end{tabular}

Note: The table reports the estimated sample correlations (1991:7-2003:6) between the risk factors used in the asset pricing tests in equations (8)-(10). $R_{m}, H M L$ and $S M B$ denote the returns on the market, High-Minus-Low (book-to-market) and Small-Minus-Big (size) portfolios. $V^{2}$ and $L$ denote realized volatility and logarithmic standard deviation respectively. $V_{60}^{2}, V_{120}^{2}, V_{240}^{2}, L_{60}, L_{120}$, and $L_{240}$ denote the long-run 60-day, 120-day and 240-day realized volatilities and logarithmic standard deviations respectively. The long-term realized volatilities were computed using the corresponding rolling sample squared returns.

stocks does not allow us to construct a large cross-section of portfolios for each of the firm-specific characteristic. As such, the cross-sectional tests could not be implemented with a small number of portfolios. Lastly, we use monthly data from 1991 since the low number of stocks in the late 1980s does not enable us to form the 6 size- $B / M$ Fama-French portfolios with a considerable number of stocks within each group.

The descriptive statistics for the value-weighted $S M B$ and $H M L$ risk portfolios and the 25 test portfolios are presented in table 7 . The internationally documented size premium of small-cap over large-cap stocks (Fama and French (1998)) appears to be a fact for A.S.E. also. The size zero-cost factor portfolio $S M B$ delivers a $1.18 \%$ monthly premium and the difference between the extreme small-cap portfolio and large-cap portfolios is $2.39 \%$ per month. Our data set reveals also a value premium for A.S.E. stocks from 1991 to 2003, although smaller then the size effect. The monthly sample average return for $H M L$ is $0.6 \%$ whereas the premium of the value portfolio over the growth portfolio is $2 \%$ per month. Also, the data yield a relative premium for the high dividend-yield and low price-earnings ratio portfolios. The difference between the high and low $D / Y$ portfolio is $1.36 \%$ per month and the difference between the lowest and the highest $P / E$ portfolio is 
$1.46 \%$. Finally, and as it was expected, winners deliver an average premium of $1.17 \%$ per month over losers. Overall, our sample reveals similar differences in the average returns of characteristics-based portfolios as those reported in other studies for the A.S.E., like Leledakis, Davidson and Karathanassis (2003), Antoniou, Galariotis, and Spyrou (2005), Theriou, Maditinos, Chatzoglou and Anggelidis (2005), and Kyriazis and Diacogiannis (2007).

Lastly, table 8 reports the sample correlation matrix of the alternative risk factors. The low estimated correlation coefficients indicate that the factors can be used as independent sources of aggregate risk in our asset pricing tests and, as a result, portfolio betas can be safely estimated from the multivariate specification in equation (9).

\section{B. The Cross-Section of Returns and Market, Value, Size and Realized Volatility Risks}

Table 9 presents the full-sample estimated betas on the various factors. More specifically, we report the values of the estimated portfolio loadings on market return $\beta_{m}$, the two Fama-French aggregate size and value factors $\beta_{S M B}$ and $\beta_{H M L}$, and the different measures of realized risk: 60-day, 120-day and 240-day realized volatility $\beta_{V^{2}}$ and logarithmic standard deviation $\beta_{L}$ respectively.

Consistent with the existing literature that attacks the empirical validity of the CAPM our estimates of market betas show a low spread across portfolios indicating a relatively flat relationship between market loadings and the cross-section of average stock returns. In contrast, the spread in betas for the Fama-French factors are large and with the correct sign both for the value and size portfolios. The difference in $\beta_{S M B}$ between the value and growth portfolio is 0.288 and the difference between the betas in smallest and largest portfolio is 1.460. Similarly, the cross-sectional difference in $\beta_{H M L}$ for value and growth stocks is 0.494 whereas for small-cap and large-cap stocks is 0.216 . Our findings support the view of Fama and French (1993) that small and growth stocks are more risky and carry a premium for their exposure to economy-wide value and size factors. Finally, and for the $15 \mathrm{D} / \mathrm{Y}, \mathrm{P} / \mathrm{E}$ and momentum portfolios we observe low spreads in the estimated market and $S M B$ betas. However, there exist economically significant differences in the estimated loadings for the aggregate value mimicking factor $H M L(-0.206,0.277$ and 0.806 respectively) in favor of an aggregate value risk factor in A.S.E. returns. It is notable that the negative values of $S M B$ and $H M L$ betas of the largest stock portfolios 


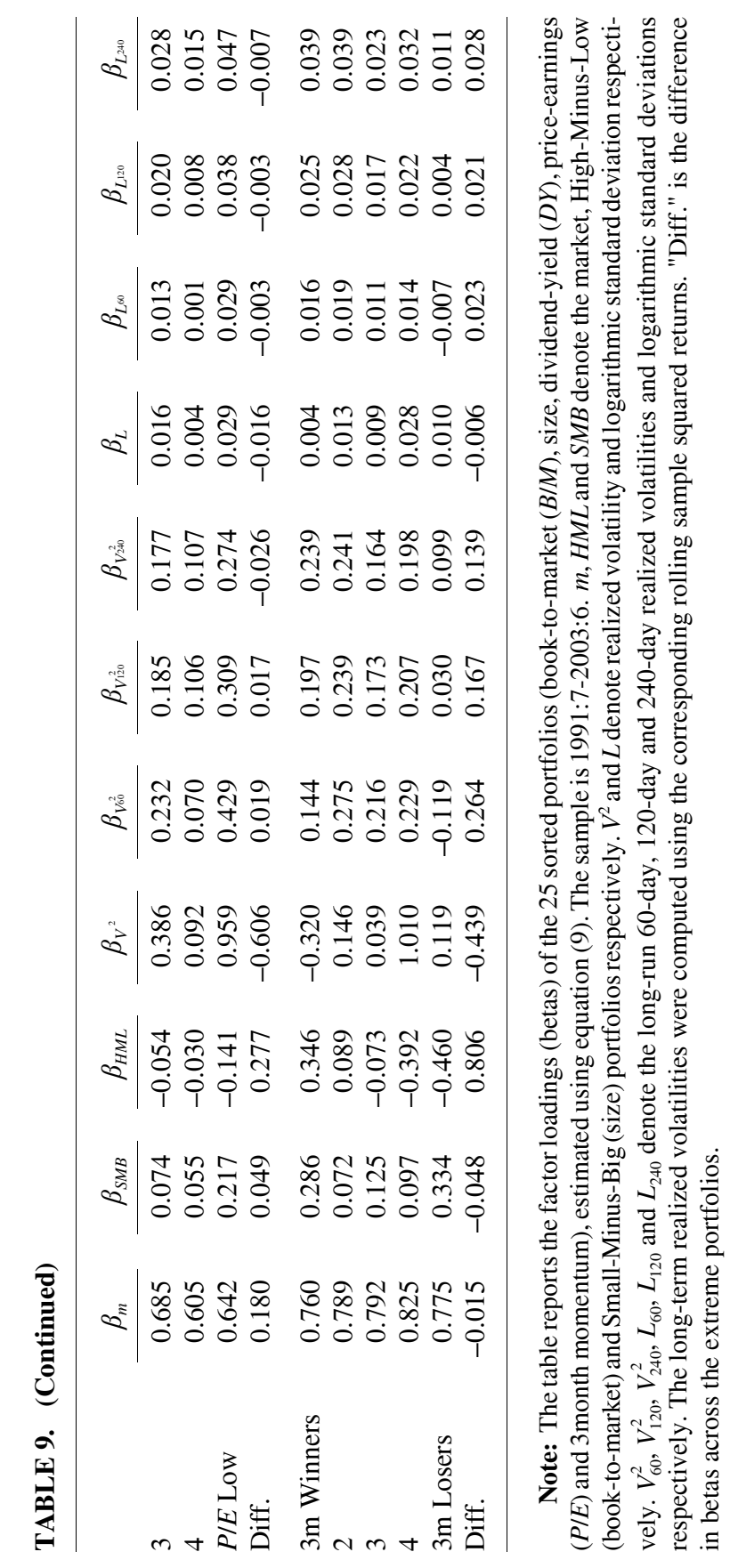


are consistent with the findings of Fama and French (1993) and Antoniou, Galariotis, and Spyrou (2005).

The estimated loadings on realized market variance $\beta_{v^{2}}$ and logarithmic market standard deviation $\beta_{L}$ are shown in columns 4 to 11 . Value portfolios appear to have much higher sensitivities with realized risk than growth stocks and the difference between the extreme portfolios is 0.938 for contemporaneous realized volatility and 0.024 for the contemporaneous realized log standard deviation. Also, there exist considerable spreads for the long-horizon defined measures of realized risk although the levels and therefore the differences in the estimated betas are smaller that their contemporaneous counterpart. Our estimation results deliver also a positive difference between the long-term volatility factor loadings for the small-large, low-high $D / Y$ and winners-losers portfolios. However, while the contemporaneous correlation of these zero-cost portfolios with aggregate volatility is negative the estimates become positive when realized risk is measured over longer periods.

The main empirical results of the cross-sectional regressions in (10) are presented in table 10. For each specification we report the estimate of the beta prices of risk $(\gamma \mathrm{s})$, the EIV-corrected standard error (in parentheses) and the time-series average adj- $R^{2}$ of the monthly asset pricing regressions. The first row of Panel A reports the results for the static single-factor static CAPM. Our data provide further evidence in the asset pricing literature about the failure of the CAPM (see, for example, Fama and French $(1992,2004)$ ). The model delivers a highly insignificant market risk premium which indicates a flat relationship between market betas and average excess portfolio returns. Our results are consistent with earlier empirical studies that provide evidence against the static CAPM in the Greek stock market. For example, Karanikas, Leledakis and Tzavalis (2006), using a similar sample, found that market betas have no explanatory power over the cross-section of a set of individual stocks. Further, Leledakis, Davidson and Karathanassis (2003), Theriou, Maditinos, Chatzoglou, and Anggelidis (2005), Antoniou, Galariotis, and Spyrou (2005) and Kyriazis and Diacogiannis (2007), all find it hard to give support to a positive return-market beta linear relationship. ${ }^{13}$

13. In order to identify asymmetries in the relationship between realized risk and average returns, and the pricing of downside risk, we followed Ang, Chen and Xing (2006) and estimated regressions of average excess portfolio returns on downside betas. However, the results did not provide any evidence for the pricing of downside risk in A.S.E. These results are available upon request. 
Although, the single $V^{2}$ factor is not priced when used alone, it is highly significant $(1 \%$ level) in the long-horizon regressions, the estimated beta prices are quite stable in all specifications ranging from 0.0228 for the 60 -day regression to 0.385 in the 240 -day regression respectively and it captures almost a third of the cross-sectional variation in average excess returns. Our results appear to be consistent with the hypothesis that the exposure to aggregate realized market risk is priced in the cross-section of A.S.E. portfolio returns.

The inclusion of $H M L$ and $S M B$ betas in the cross-sectional regression improves the explanatory performance of $(10)$ and the adj. $-R^{2}$ increases close to $60 \%$ for all horizon specifications. In this full specification the $V^{2}$ coefficient becomes smaller in magnitude ranging from 0.0052 to 0.0406 exhibiting a strict monotonic pattern as the horizon increases but it loses some of its statistical significance. The premium for the size factor $S M B$ is positive and highly significant for the contemporaneous and 60-day regression while its significance falls with when longer horizon realized volatility betas are included. However, the estimates are quite stable across specifications. The $H M L$ factor delivers negative and small in magnitude premia in all regressions and they are significant at only a $10 \%$ level. The results indicate that our search for a realized market variance risk factor, that could be a priced in A.S.E. returns, is independent of any market, size or value risk effects.

The asset pricing results when logarithmic standard deviation is used as a priced factor $(V O L=L$ in equations (8) to (10)) are presented in Panel B. The empirical findings are clearer since the $L$-factor appears to be better priced both in the contemporaneous and the long-horizon specification of (10). When it used alone, it increases the explained cross-sectional variation of average returns to $21 \%$ with a highly significant 0.3789 price of beta risk for the contemporaneous risk specification, and average adj. $-R^{2}$ increases to $40 \%$ in long-horizon setting. The pricing errors are significant indicating that other factors may be important for the cross-section of returns. When we include the Fama-French factors the beta market price of risk $\gamma_{m}$ becomes positive but it is still insignificant whereas price of realized log standard deviation beta risk is significant at a $5 \%$ level with stable values of $0.2972,0.2950,0.2539$ and 0.2182 for the contemporaneous, 60-day, 120-day and 240-day regressions respectively, and the explained cross-sectional variation in returns increases to $60 \%$. The statistical significance and the stability of the size factor premia $\gamma_{S M B}$ in all regressions indicate that there exist size effects in A.S.E. that are unrelated to risks associated with realized volatility (premia range from 


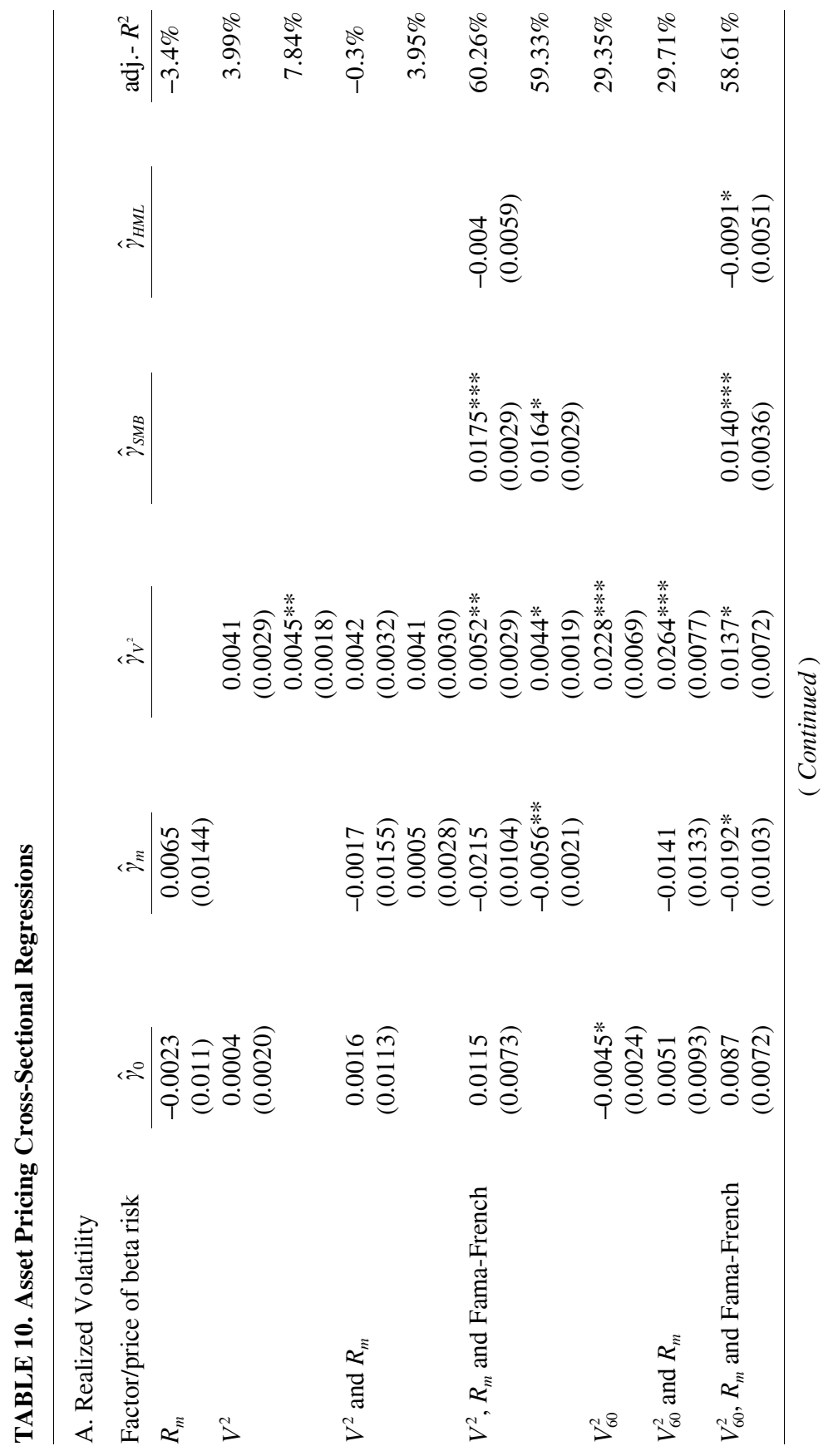




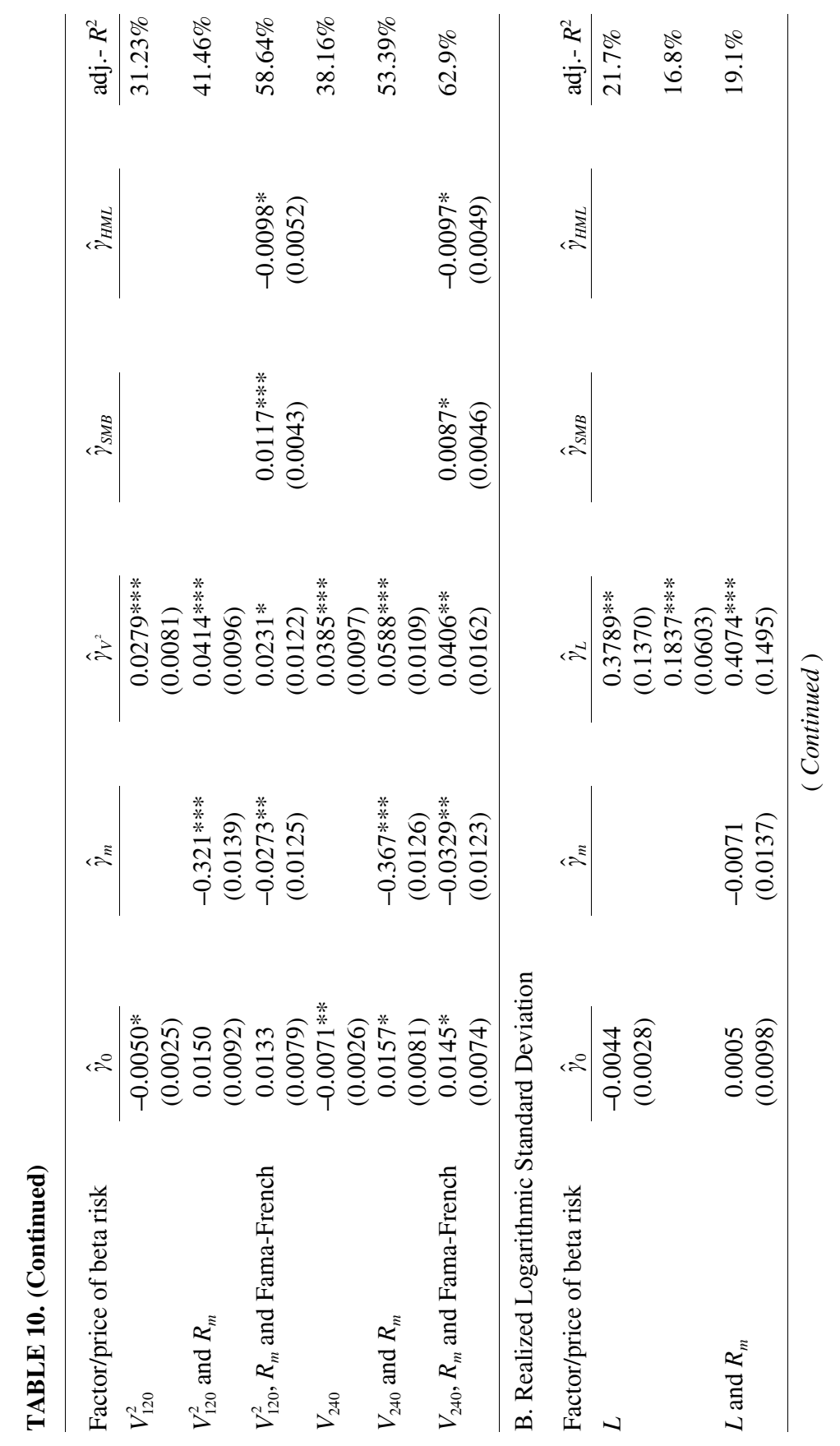




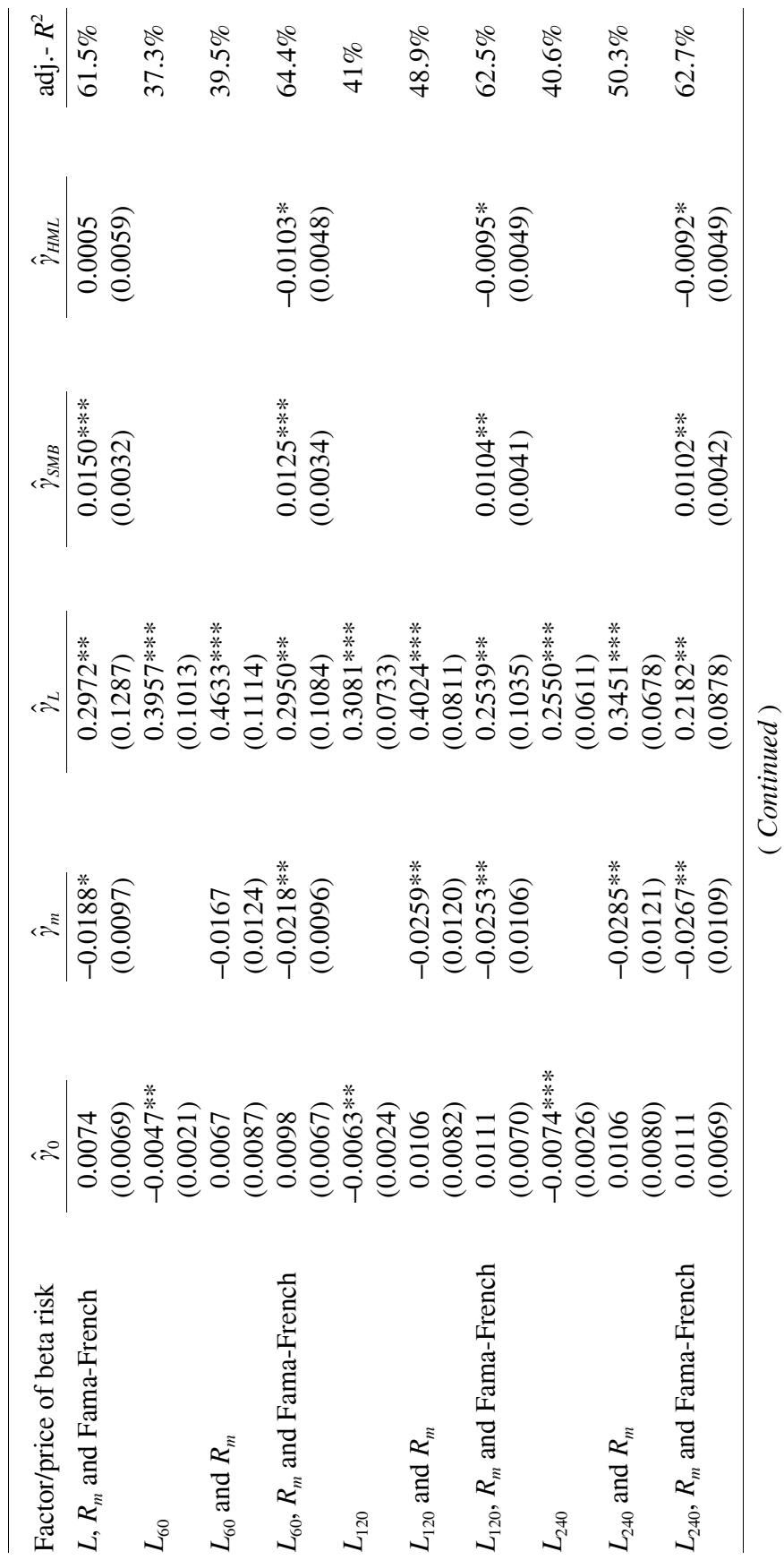




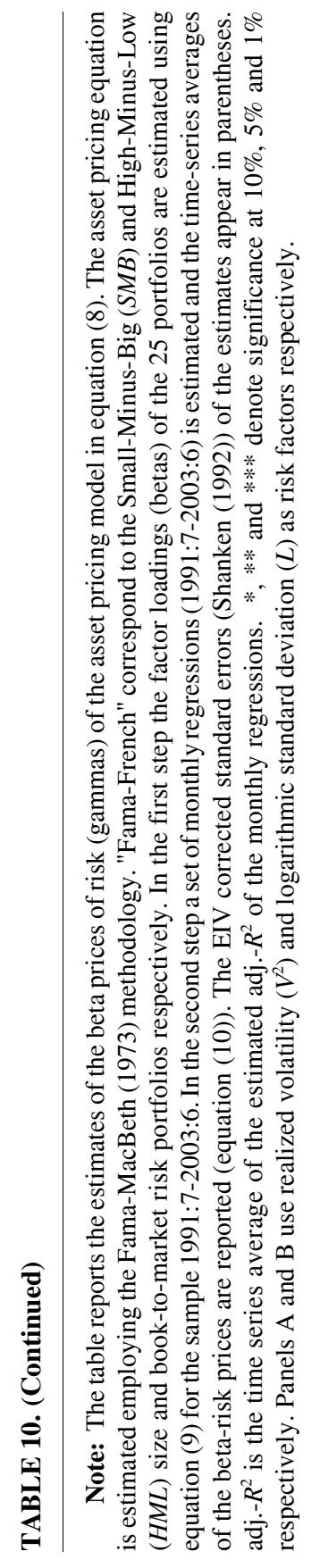


0.0102 to 0.0150$)$. However, and as in the realized volatility case in Panel A, the prices of risk for the value factor are small, negative and significant only at a $10 \%$ level and as a result we cannot infer about the economic importance of aggregate book-to-market mimicking factor to capture any of the cross-sectional variation in A.S.E. returns.

Concluding, our empirical results can be summarized as follows. There is a clear linear relationship between average portfolio returns and loadings on realized aggregate volatility (either realized volatility or logarithmic standard deviation), and, further, this relationship is independent of any market, size or book-to-market effects as these are captured by the three-factor Fama-French (1993) model. The spread in full-sample (1991-2003) estimated betas with both contemporaneous and long-horizon (60-day, 120-day and 240-day) realized risk capture a large part of the cross-sectional variation in A.S.E. returns and generate large in magnitude and statistically significant premia. However, there is clear space for the Fama-French aggregate size factor $S M B$ but we cannot safely infer about the importance of the aggregate value factor $H M L$ when realized market risk is considered.

\section{Conclusions}

This paper uses a newly developed data set of daily, value-weighted stock returns from the Greek stock market, constructs and analyzes the properties of the monthly realized volatility of the Athens Stock Exchange (A.S.E.) from 1985 to 2003. This work is related to three lines of the volatility literature: the first deals with the construction and properties of model-free measures of volatility while the second examines the, so-called, leverage effect while the third examines the role of time-varying market risk as a priced factor. We find that the realized volatility series exhibits short memory and its distribution is not Gaussian while the realized log standard deviation series exhibit short memory but probably has an underlying Gaussian distribution. These results are conformable with the existing literature. We also find evidence in favor of the presence of volatility feedback effects and asymmetries between lagged returns and volatility: not only there is strong evidence of financial leverage, but there appears that the A.S.E. market has a time-varying risk premium that is an increasing function of volatility.

As far as the third line is concerned this paper examines whether the various definitions of market realized risk can serve as competing 
aggregate risk factors, in an unconditional asset pricing model, that could explain the cross-sectional variation in average returns on firm-characteristic single-sorted portfolios in the Greek stock market. The results indicate a clear linear relationship between loadings (betas) on realized aggregate volatility (either realized volatility or logarithmic standard deviation) and this relationship is independent of any market, size or book-to-market effects as these are captured by the three-factor Fama-French (1993) model. To our knowledge this is the first study that examines such relationships in the Greek stock market.

According to the standard intertemporal asset pricing theory the high explanatory power of realized risk (either measured by realized volatility of logarithmic standard deviation) in the asset pricing tests indicates that there should be a link between current realized risk and expected macroeconomic conditions and/or changes in the future set of investment opportunities; a potential extension of our research, using the computed realized volatility series, could be the examination of this links of realized market risk with the future state of the economy.

Accepted by: Prof. P. Theodossiou, Editor-in-Chief, March 2008

\section{References}

Andersen T., and Bollerslev, T. 1998. Answering the skeptics: Yes, standard volatility models do provide accurate forecasts. International Economic Review 39: 885-905.

Andersen, T.; Bollerslev, T.; Diebold, F.; and Labys, P. 2001a. The distribution of exchange rate volatility. Journal of the American Statistical Association 96: 42-55.

Andersen, T.G.; Bollerslev, T.; Diebold, F.X.; and Labys, P. 2001b. Modelling and forecasting realized volatility. NBER working paper no. 8160. Cambridge, Mass.: National Bureau of Economic Research.

Andersen, T.G.; Bollerslev, T.; Diebold, F.X.; and Labys, P. 2001c. The distribution of stock return volatility. Journal of Financial Economics 61: 43-76.

Ang, A.; Chen, J.; and Xing, Y. 2006. Downside risk. Review of Financial Studies 19: 1191-1239.

Ang, A.; Hodrick, R.; Xing Y.; and Zhang, X. 2006. The cross-section of volatility and expected returns. Journal of Finance 61: 259-299.

Antoniou, A.; Galariotis, E.; and Spyrou S. 2005. Contrarian profits and the overreaction hypothesis: the case of the Athens Stock Exchange. European Financial Management 11: 71-98.

Apergis, N., and Eleftheriadou, S. 2001. Stock returns and volatility: Evidence from the Athens Stock market index. Journal of Finance and Economics 25: 
$50-61$.

Athanassiou, E.; Kollias, C.; and Syriopoulos, T. 2006. Dynamic volatility and external security related shocks: The case of the Athens Stock Exchange. Journal of International Financial Markets, Institutions and Money 16: 411-424.

Barkoulas, J.; Baum, Ch.; and Travlos, N. 2000. Long memory in the Greek stock market. Applied Financial Economics 10. 177-184.

Barndorff-Nielsen, O., and Shephard N. 2001a. Non-gaussian OrnsteinUhlenbeck based models and some of their uses in financial economics. Journal of the Royal Statistical Society: Series B, 63: 167--241.

Barndorff-Nielsen, O., and Shephard N. 2001b. How accurate is the asymptotic approximation to the distribution of the realized volatility. Mimeo.

Banz, R. 1981. The relationship between return and market value of common stocks. Journal of Financial Economics 9: 3-18.

Basu, S. 1977. Investment performance of common stocks in relation to their price-earnings ratios: A test of the efficient market hypothesis. Journal of Finance 32: 663-682.

Bekaert, G., and Wu, G. 2000. Asymmetric volatility and risk in equity markets. Review of Financial Studies 13: 1-42.

Bollerslev, T., and Zhou, H. 2006. Volatility puzzles: A simple framework for gauging return-volatility regressions. Journal of Econometrics 131: 123-150.

Campbell, J. 1996. Understanding Risk and Return. Journal of Political Economy 104: 298-345.

Campbell, J., and Hentschel, L. 1992. No News is Good News: An Asymmetric Model of Changing Volatility in Stock Returns. Journal of Financial Economics 31: 281-318.

Campbell, J.; Lettau, M.; Malkiel, B.G.; and Xu, Y. 2001. Have individual Stocks become more volatile? An empirical exploration of idiosyncratic risk. Journal of Finance 56: 1-43.

Campbell, J.; Polk, C.; and Vuolteenaho, T. 2007. Growth or glamour? Fundamentals and systematic risk in stock returns. Harvard University unpublished paper.

Chen, J. 2003. Intertemporal CAPM and the Cross-Section of Stock Returns. University of Southern California, unpublished monograph.

Chortareas, G.; McDermott, J.; and Ritsatos, T. 2000. Stock market volatility in an emerging market: Further evidence from the Athens Stock Exchange. Journal of Business Finance \& Accounting 27: 983-1002.

Diacogianinis, G.; Tsiritakis, E.; and Manolas G. 2001. Macroeconomic factors and stock returns in a changing economic framework: The case of the Athens Stock Exchange. Managerial Finance 27: 23-41.

Daniel, K., and Titman, S. 1997. Evidence on the characteristics of cross sectional variation in stock returns. Journal of Finance 52: 1-33.

Daniel, K.; Titman, S.; and Wei, J. 2001. Explaining the cross-section of stock 
returns in Japan: Factors or characteristics? Journal of Finance 56: 743-766.

Dimson, E.; Nagel, S.; and Quigley, G. 2003. Capturing the value premium in the U.K. 1955-2001. Financial Analysts Journal 59: 35-45.

Drimbetas, E.; Sariannidis, N.; and Porfiris, N. 2007. The effect of derivatives trading on volatility of the underlying asset: evidence from the Greek stock market Applied Financial Economics 17: 139-148.

Engle, R., and Ng, V. 1993. Measuring and Testing the Impact of News on Volatility. Journal of Finance 48: 1749-1778.

Fama, E., and MacBeth J. 1973. Risk, Return and Equilibrium: Empirical Tests. Journal of Political Economy 71: 607-636.

Fama, E., and French, K. 1993. Common Risk Factors in the Returns on Stocks and Bonds. Journal of Financial Economics 33: 3-56.

Fama, E., and French, K. 1996. Multifactor explanations of asset pricing anomalies. Journal of Finance 51: 55-84.

Fama, E., and French, K. 1997. Industry costs of equity. Journal of Financial Economics 43: 153-193.

Fama, E., and French, K. 1998. Value versus Growth: The International Evidence. Journal of Finance 53: 1975-2000.

Floros, C., and Vougas, D. 2006. Index futures trading, information and stock market volatility: The case of Greece. Derivatives: Use, Trading and Regulation 12: 146-166.

French, K.; Schwert, G.; and Stambaugh, R. 1987. Expected stock returns and volatility. Journal of Financial Economics 19: 3-30.

Guo, H., and Whitelaw, R. 2006. Uncovering the risk-return relation in the stock market. Journal of Finance 61: 1432-1462.

Griffin, J. 2001. Are the Fama and French Factors Global or Country Specific? Review of Financial Studies 15: 783-803.

Jegadeesh, N., and Titman, S. 1993. Returns to buying winners and selling losers: Inlplications for stock market efficiency. Journal of Finance 48: 65-91.

Karanikas, E.; Leledakis, G.; and Tzavalis E. 2006. Structural changes in expected stock returns relationships: Evidence from ASE. Journal of Business Finance \& Accounting 33: 1610-1628.

Kavussanos M. G., and Dockery E. 2001. A multivariate test for stock market efficiency: the case of ASE. Applied Financial Economics 11: 573-579.

Kyriazis, D., and Diacogiannis, G. 2007. Testing the performance of value strategies in the Athens Stock Exchange. Applied Financial Economics 17: 1511-1528.

Lakonishok, J.; Shleifer, A.; and Vishny, R. 2004. Value and growth investing: Review and update. Financial Analysts Journal 60: 71-86.

Leledakis, G.; Davidson, I.; and Karathanassis, G. 2003. Cross-sectional estimation of stock returns in small markets: The case of the Athens Stock Exchange. Applied Financial Economics 13: 413 - 426. 
Lewellen, J. 1999. The Time-Series Relations Among Expected Return, Risk, and Book-to-Market. Journal of Financial Economics 54: 5-43.

Liew, J., and Vassalou, M. 2000. Can book-to-market, size and momentum be risk factors that predict economic growth? Journal of Financial Economics 57: 221-245.

Maris, K.; Pantou, G.; Nikolopoulos, K.; Pagourtzi, E.; and Assimakopoulos V. 2004. A study of financial volatility forecasting techniques in the FTSE/ASE 20 index. Applied Economics Letters 11: 453-457.

Merton, R. 1973. An Intertemporal Capital Asset Pricing Model. Econometrica 41: 867-887.

Merton, R. 1980. On Estimating the Expected Return on the Market: An Exploratory Investigation. Journal of Financial Economics 8: 323-361.

Nelson, D. 1991. Conditional Heteroskedasticity in Asset Returns: A New Approach. Econometrica 59: 347-370.

Petkova, R. 2006. Do the Fama-French factors proxy for innovations in predictive variables? Journal of Finance 61: 581-612.

Phylaktis K.; Kavussanos M.; and Manalis G. 1999. Price Limits and Stock Market Volatility in the Athens Stock Exchange. European Financial Management 5: 69-84.

Poterba, J., and Summers L. 1986. The Persistence of Volatility and Stock Market Fluctuations. American Economic Review 76: 1142-1151.

Pindyck, R.S. 1984. Risk, Inflation, and the Stock Market. American Economic Review 74: 334--351.

Schwert, G. 1990. Stock Market Volatility. Financial Analysts Journal: May-June: 23-34.

Shanken, J. 1992. On the Estimation of Beta-Pricing Models. Review of Financial Studies 5: 1-33.

Shanken, J., and Weinstein, M.I. 2006. Economic forces and the stock market revisited. Journal of Empirical Finance 13: 129-144.

Siourounis, G. 2002. Modelling volatility and testing for efficiency in emerging capital markets: the case of the Athens stock exchange. Applied Financial Economics 12: 47-55.

Travlos, N. 1992. Athens Stock Exchange: Creation of a Stock Data Bank and Risk-Returns Characteristics for the Period 1981-1990. University of Piraeus, unpublished monograph.

Theriou, N.; Maditinos, D.; Chatzoglou, P.; and Anggelidis V. 2005. The cross-section of expected stock returns: An empirical study in the Athens stock exchange. Managerial Finance 31: 58-78.

Vougas, D. 2004. Analysing long memory and volatility of returns in the Athens stock exchange. Applied Financial Economics 14: 457-460. 